CAMILLA PARENTE DIAS

Acordos pay-for-delay no mercado farmacêutico:

uma análise à luz do Direito Antitruste e Comparado

Dissertação de Mestrado

Orientador: Professor Doutor Roberto Augusto Castellanos Pfeiffer

UNIVERSIDADE DE SÃO PAULO

FACULDADE DE DIREITO

São Paulo - SP

2020 

CAMILLA PARENTE DIAS

\section{ACORdOS PAY-FOR-DELAY NO MERCADO FARMACÊUTICO: UMA ANÁLISE À LUZ do Direito ANTITRUSTE E COMPARAdo}

Dissertação apresentada à Banca Examinadora do Programa de PósGraduação em Direito, da Faculdade de Direito da Universidade de São Paulo, como exigência parcial para obtenção do título de Mestre em Direito, na àrea de concentração Direito Comercial, sob a orientação do Prof. Dr. Roberto Augusto Castellanos Pfeiffer.

UNIVERSIDADE DE SÃO PAULO

FACULDADE DE DIREITO

São Paulo - SP 
Autorizo a reprodução e divulgação total ou parcial deste trabalho, por qualquer meio convencional ou eletrônico, para fins de estudo e pesquisa, desde que citada a fonte.

Dias, Camilla Parente

Acordos pay-for-delay no mercado farmacêutico:

uma análise à luz do Direito Antitruste e Comparado ;

Camilla Parente Dias ; orientador Roberto Augusto

Castellanos Pfeiffer -- São Paulo, 2020.

$282 \mathrm{p}$.

Dissertação (Mestrado - Programa de Pós-Graduação em

Direito Comercial) - Faculdade de Direito,

Universidade de São Paulo, 2020.

1. Direito Antitruste. 2. Patentes farmacêuticas.

3. Acordos pay-for-delay. 4. Infração à ordem

econômica. 5. Contratos associativos. I. Pfeiffer,

Roberto Augusto Castellanos, orient. II. Título. 
Nome: DIAS, Camilla Parente

Título: Acordos pay-for-delay no mercado farmacêutico: uma análise à luz do direito antitruste e comparado.

Dissertação de mestrado apresentada ao Programa de PósGraduação da Faculdade de Direito da Universidade de São Paulo, para a obtenção do título de Mestre em Direito.

Aprovada em:

\section{Banca Examinadora}

Presidente: Roberto Augusto Castellanos Pfeiffer.

Instituição: Universidade de São Paulo

Prof. Dr.

Instituição:

Julgamento:

Prof. Dr.

Instituição:

Julgamento:

Prof. Dr.

Instituição:

Julgamento: 

À minha família,

Por estar sempre ao meu lado 



\section{AGRADECIMENTOS}

Agradeço, primeiramente, ao Professor Roberto Augusto Castellanos Pfeiffer pela honra de sua orientação. Sou grata por todo aprendizado, pelas conversas produtivas, pelos conselhos preciosos e, pela confiança depositada sobre mim.

Agradeço também ao Professor Marcelo Proença pelos ricos conselhos e por ter me apoiado e me incentivado ao longo desta jornada. Aqui, gostaria de citar uma frase de Isaac Newton aprendida em suas aulas "se eu vi mais longe, foi por estar sobre ombros de gigantes". Obrigado Professor Proença e Professor Pfeiffer por terem sido meus gigantes.

Gostaria de agradecer também à Professora Juliana Krueger Pela pelas contribuições indispensáveis ao desenvolvimento desta dissertação.

E a todos os Professores que participaram da construção do meu saber, principalmente aos Professores da Faculdade de Direito da Universidade de São Paulo, a qual eu me orgulho muito.

Finalmente, agradeço à minha família. Em especial, aos meus irmão queridos e às mulheres guerreiras da minha vida, minha mãe, por sempre estar ao meu lado, e minha avó, que mesmo longe, sempre está perto, e são a eles que dedico este trabalho. 



\section{RESUMO}

DIAS, Camilla Parente. Acordos pay-for-delay no mercado farmacêutico: uma análise à luz do Direito Antitruste e Comparado. 2020. 280 p. Dissertação (Mestrado) - Programa de Pós-Graduação em Direito da Universidade de São Paulo, São Paulo, 2020.

A presente dissertação tem por objeto o estudo de acordos patentários entre farmacêuticas que produzem e comercializam medicamentos de marca e farmacêuticas que produzem e comercializam medicamentos genéricos, nos quais as primeiras pagam para as últimas postergarem sua entrada no mercado. O pagamento envolvido nos acordos é chamado de pagamento reverso, isto porque sua direção é do titular da patente para aquele que deseja entrar no mercado. As primeiras investigações instauradas por autoridades de defesa da concorrência se deram nos Estados Unidos da América (EUA), onde o quadro regulatório propiciou um ambiente favorável à prática dos acordos. Devido às legislações regulatórias específicas, os acordos nos EUA nasceram no âmbito judicial, como instrumento solucionador de litígios patentários. Também por esse motivo, os acordos pay-for-delay, em sua origem, eram tratados como meios legítimos para colocar fim a conflitos, momento em que sua análise à luz do Direito Antitruste ainda era estranha. Este cenário veio a se modificar substancialmente após decisão da Suprema Corte dos EUA sedimentando entendimento sobre o potencial lesivo dos acordos. A Comissão Europeia também desempenhou papel fundamental na investigação de acordos pay-for-delay, quando, em 2008, lançou um inquérito no setor farmacêutico para desvendar os motivos para a falta de inovação e diversidade na indústria farmacêutica. $\mathrm{O}$ cenário brasileiro, ao contrário do que aconteceu nos EUA e na União Europeia, não foi propício, por muito tempo, para a ocorrência da prática. A legislação de propriedade industrial chegou no Brasil tardiamente, e a inovação do setor farmacêutico não era tão significativa como naquelas jurisdições. Não obstante a ausência da conduta em território nacional, seus efeitos podem penetrar nas fronteiras brasileiras por meio da importação de medicamentos objetos dos acordos. Neste contexto, a conduta é analisada à luz da legislação antitruste pátria, mais especificamente, sua subsunção nas hipóteses de infração à ordem econômica do artigo 36 da Lei no 12.529/11. Por fim, mas não menos importante, vislumbra-se destinar aos acordos o controle preventivo, de maneira a evitar seus efeitos danosos à saúde pública e aos consumidores.

Palavras-chave: Propriedade Intelectual. Direito Concorrencial. Indústria Farmacêutica. Infração à ordem econômica. Acordos Pay-for-Delay. Contratos Associativos. 


\begin{abstract}
DIAS, Camilla Parente. Pay-for-delay agreements in the pharmaceutical sector: an analysis in light of Antitrust and Comparative law. 2020. Thesis (Master) - Postgraduate Program degree in Law of Law School of University of São Paulo, São Paulo, 2020.

This master thesis aims at studying patent settlement agreements entered into by and between pharmaceutical companies that manufacture and sell brand-name drugs and pharmaceutical companies that manufacture and sell generic drugs, under which the former provides the latter with payment for delaying its own market entry. The payment performed under said agreements is also known as reverse payment, since it goes from the patent holder to the entrant. Pioneer antitrust investigations took place in the United States of America (USA), where the regulatory framework used to provide a favorable environment for the practice of such agreements. Due to specific regulatory rules, the US agreements were born in the courts, as a mechanism to solve patent litigation. Also for this reason, a pay-for-delay agreement had originally been deemed as a lawful mean to bring an end to a dispute, at a time when the antitrust law was not applied to it yet. This scenario has substantially changed after the US Supreme Court confirmed the potential harm of the agreements. The European Commission also played a key role in investigating pay-fordelay agreements. In 2008, it conducted an inquiry in the pharmaceutical sector to discover the reasons for the lack of innovation and diversity in the pharmaceutical industry. Unlike the US and the European Union, the Brazilian scenario did not encourage, for a long time, to such practice. The industrial property legislation arrived late in Brazil, and innovation in the pharmaceutical sector has not been as significant as in those jurisdictions. Notwithstanding the absence of said conduct in the national territory, its effects can penetrate the Brazilian borders through the import of drugs involved in the the pay-fordelay settlement agreements. In this context, the practice is reviewed in light of the national antitrust legislation and, more specifically, its section about the potential events of violation of the economic order under article 36 of Law No. 12.529/11. Lastly, it is proposed to apply the preventive control to the agreements in order to avoid its harmful effects on public health and consumers.
\end{abstract}

Keywords: Intellectual Property; Antitrust Law; Pharmaceutical Industry; Antitrust Violation; Pay-for-Delay Agreements; Association Contract. 


\section{LISTA DE FIGURAS}

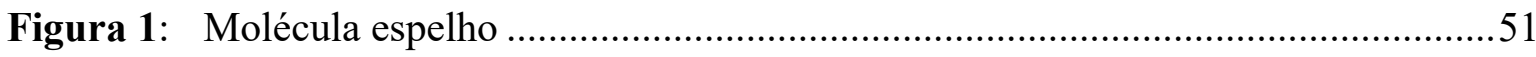

Figura 2: Evolução do Market Share - Nexium e Prilosec ...............................................52

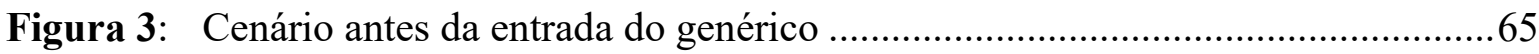

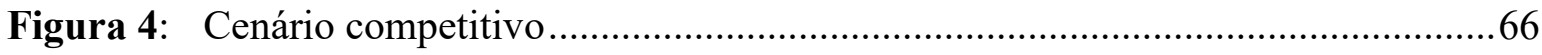

Figura 5: Cenário com pagamento de exclusão...................................................................66

Figura 6: Demonstração do custo transferido ao consumidor ...........................................67

Figura 7: Acordo de Patentes por Categoria (janeiro 2016 - dezembro 2016) ...............116

Figura 8: Economia dos consumidores entre 2001 e 2019 devido aos genéricos ...........269

Figura 9: Evolução dos acordos de patente pré e pós decisão Actavis ............................271

Figura 10: Concorrência de genéricos e preço de medicamentos .....................................273 



\section{SUMÁRIO}

INTRODUÇÃO

1 ACORDOS PAY FOR DELAY E SUA CONTEXTUALIZAÇÃO: PROPRIEDADE INDUSTRIAL, DIREITO DA CONCORRÊNCIA E O MERCADO FARMACÊUTICO .29

1.1 Sistema patentário e seu fundamento econômico ..................................................30

1.2 Da interface entre P.I. e Concorrência ................................................................34

1.3 Indústria farmacêutica e suas estratégias ..............................................................37

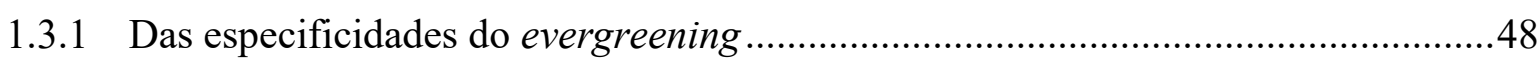

1.3.2 Do abuso do direito de petição (Sham Litigation) ................................................52

1.4 Políticas públicas de incentivo à competição originais-genéricos ........................55

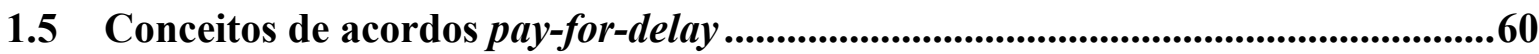

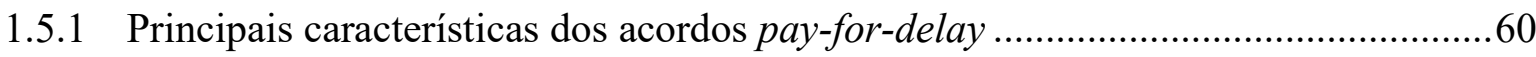

1.5.2 Dos incentivos econômicos para a celebração dos acordos com pagamento reverso 63

2 OS ACORDOS PAY-FOR-DELAY E AS INVESTIGAÇÕES NOS EUA ...............69

2.1 Quadro regulatório: Hatch-Waxman Act ..............................................................70

2.2 O caso que desencadeou as investigações: Caso In re Cardizem CD.....................75

2.3 Divergências dos posicionamentos das autoridades dos EUA..............................77

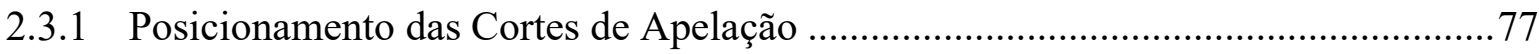

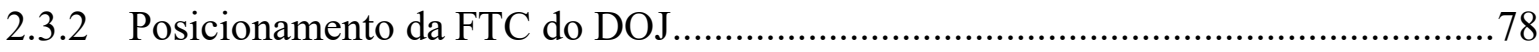

2.4 Do leading case FTC $x$ Actavis ..........................................................................8

2.5 Análise sob a regra da razão e as potenciais justificativas que podem ser alegadas pelas empresas farmacêuticas........................................................................83

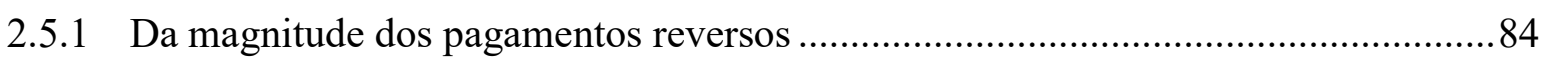

2.5.2 Casos In re Bristol-Myers Squibb Co. e Schering-Plough Corp. v. FTC .................8 84

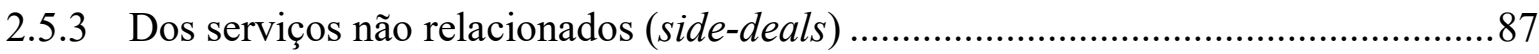

2.6 Entrada do genérico dentro da vigência da patente (Patent-Term Split Agreement)......................................................................................................................................89

2.7 Conceito de pagamento reverso à luz do caso Actavis x FTC .............................91

2.8 Das novas modalidades de pagamento reverso - não pecuniário ........................93

2.8.1 Cláusulas de No-AG (No-Authorized Generic) e casos...........................................94 


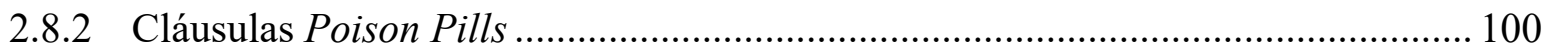

2.8.3 Não cobrança de danos por infração patentária causados pelo genérico................. 104

3 OS ACORDOS PAY-FOR-DELAY E AS INVESTIGAÇÕES NA COMISSÃO EUROPEIA ......................................................................................................................109

3.1 Do inquérito setorial instaurado pela Comissão Europeia ……………………...... 109

3.2 Das conclusões da Comissão ……...............................................................112

3.3 Quadro regulatório .................................................................................................. 114

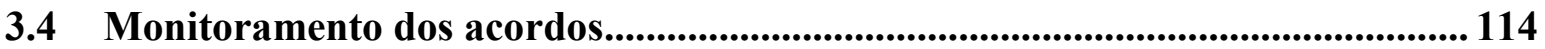

3.5 Subdivisão dos acordos conforme sua licitude: Categoria A/ Categoria BI/

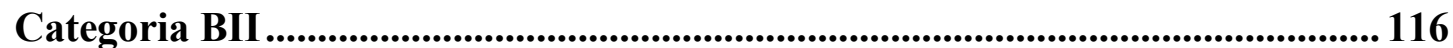

3.5.1 Critérios considerados para analisar a ilicitude dos acordos ................................ 117

3.6 Casos relevantes analisados pela Comissão Europeia ............................................... 118

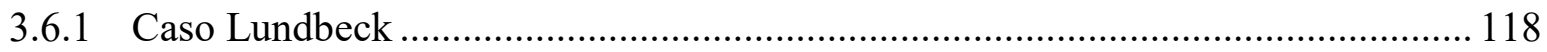

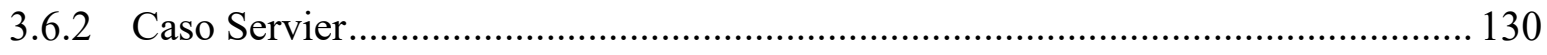

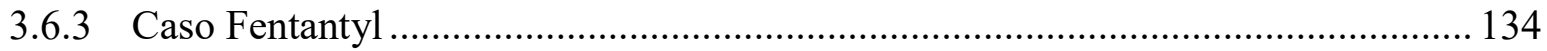

3.7 Distinções entre as abordagens adotadas pelos EUA e pela UE ........................... 137

4 CENÁRIO BRASILEIRO ...................................................................................141

4.1 Da competência do CADE para analisar acordos de patentes homologados pelo judiciário ...................................................................................................................... 141

4.2 Casos e práticas anticompetitivas no mercado farmacêutico analisados pelo CADE

4.3 Do acordo patentário no mercado de revista de passatempo analisado pelo CADE 148

4.4 Da competência do CADE para analisar acordos celebrados fora do território brasileiro 152

4.4.1 Do artigo $2^{\circ}$ da Lei 12.529 e da teoria dos efeitos............................................. 152

4.4.2 Cartéis internacionais e das hipóteses que atraem competência do CADE............. 154

4.4.3 Dos efeitos no mercado interno: das importações ................................................. 155

4.4.3.1 Caso In re Nexium ........................................................................................159

4.5 A formação dos preços dos medicamentos e a CMED ............................................ 160

4.6 Outras Autoridades com competência para análise da conduta .......................... 161

4.6.1 Da atuação do INPI e das limitações do CADE ................................................. 162

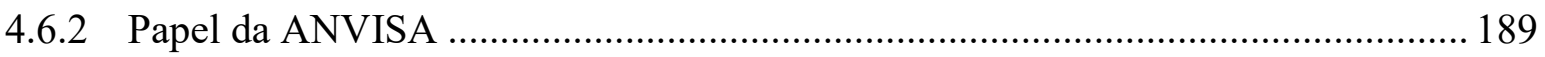




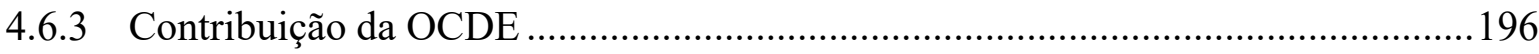

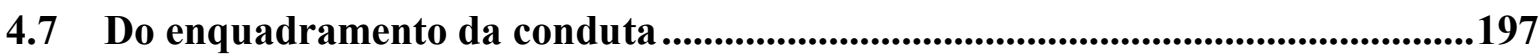

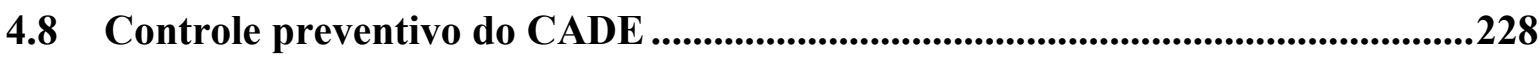

4.9 Do enquadramento do acordo pay for delay como Contrato Associativo...........233

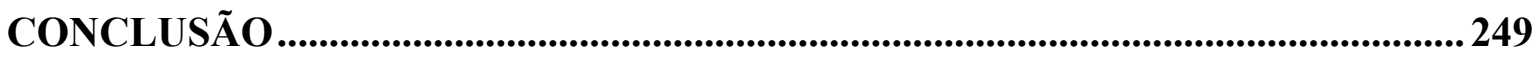

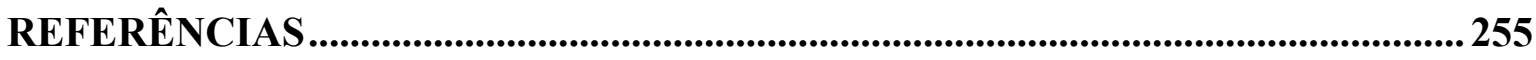

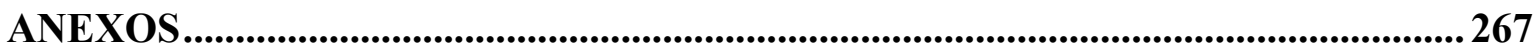

Anexo 1: Economia dos consumidores entre 2001 e 2019 devido aos genéricos .........269

Anexo 2: Evolução dos acordos de patente pré e pós decisão Actavis ...........................271

Anexo 3: Concorrência de genéricos e preço de medicamentos ..................................273

Anexo 4: Lista de Medicamentos: Primeiro registro na ANVISA em resposta à solicitação da autora.........................................................................................2275 



\section{INTRODUÇÃO}

O objeto de estudo desta dissertação são os acordos de patentes celebrados entre empresas farmacêuticas que comercializam medicamentos de marca e empresas farmacêuticas que comercializam medicamentos genéricos com vistas a solucionar conflitos patentários desencadeados no âmbito judicial ou não.

Tais acordos envolvem pagamento da empresa de marca para a de genéricos para que estas últimas posterguem sua entrada no mercado. O referido pagamento é comumente denominado pagamento reverso, tendo em vista a direção em que o pagamento flui, isto é, do detentor da patente para seu suposto infrator, para que o último não entre no mercado. Em outras indústrias, os acordos tradicionalmente envolvem pagamento daquele que deseja entrar no mercado, por exemplo, royalties, para o titular da patente.

Majoritariamente, os acordos nasceram em litígios judiciais, nos quais uma fabricante de genéricos contestava a validade de uma patente então vigente. Isso porque a concessão de uma patente pela autoridade competente indica uma presunção de validade, porém não é um direito absoluto, podendo ser questionada a qualquer tempo. De fato, constatou-se que, em média, em $75 \%^{1}$ dos casos, os genéricos saíram vitoriosos e a patente foi posteriormente anulada por vícios em sua obtenção. Como será analisado no capítulo 1 , não raramente as farmacêuticas recorrem a estratégias anticompetitivas para prolongar, indevidamente, seus direitos patentários.

As estratégias mencionadas no parágrafo anterior têm sido objeto de estudo de muitas autoridades, tanto nacionais como internacionais, a saber, ANVISA, INPI e CADE investigam, cada qual em seu âmbito de competência, práticas que podem ser lesivas ao mercado e à sociedade; a OCDE, Comissão Europeia e FTC ${ }^{2}$, também vêm intensificando

1 Elhauge, Einer; Krueger, Alex. Solving the Patent Settlement Puzzle. Cambridge, MA: Harvard/ John M. Olin Center for Law, Economic, and Business, 2012, p. 1-5. Ver também JANICKE, Paul M.; REN, LiLan. Who wins patent infringement cases. AIPLA Quartely Journal, v. 34, n. 1, p. 18-20, Winter 2006. Disponível em: <http://licensinglaw.net/Litigation_files/Paul_M_Janicke.pdf $>$. Acesso em: 25 nov. 2019, p. 8. Nesta obra, os autores demonstram que os detentores das patentes perdem em $70 \%$ dos casos e indicam que as empresas de genéricos ganham em $73 \%$ dos casos (FEDERAL TRADE COMMISSION. Generic Drug Entry Prior to Patent Expiration: an FTC study. Washington, DC: FTC, July 2002. Disponível em: < https://www.ftc.gov/sites/default/files/ documents/reports/generic-drugentry-prior-patent-expiration-ftc-study/genericdrugstudy_0.pdf $>$. Acesso em: 25 nov. 2019). Neste artigo restou demonstrado que, pelo menos, $48 \%$ dos conflitos patentários o titular da patente perde; (RBC CAPITAL MARKETS. Pharmaceuticals: Analyzing Litigation Success Rates. Toronto: RBC, 15 Jan. 2010. Disponível em: <https://amlawdaily.typepad.com/pharmareport.pdf>. Acesso em: 9 ago. 2019).

2 Federal Trade Commission (FTC) é agência regulatória dos EUA responsável pela proteção ao consumidor e por promover a competição. 
seus esforços para identificação e controle de condutas que afetam negativamente a competição no mercado farmacêutico.

Destaca-se que os litígios patentários são comumente longos, custosos e apresentam muitos riscos para as partes envolvidas, bem como demandam das autoridades julgadoras volumosos recursos estatais para decidir sobre conflitos, que, por sua natureza, perduram por extenso período.

Os acordos patentários, portanto, evitam os longos e custosos processos judiciais, o que em tese beneficiaria, ao menos de modo indireto, toda a sociedade, e, por isso, historicamente, tanto o Estado, como as empresas, consideravam os acordos um instrumento legítimo de solução de conflitos, além de vê-los com bons olhos.

Contudo, apesar de colocar fim a longas disputas, os acordos majoritariamente resultam no atraso da entrada do medicamento genérico no mercado; não por outra razão, os acordos aqui tratados ficaram conhecidos como acordos pay-for-delay.

Acontece que os respectivos medicamentos continuavam a ser comercializados no mercado de forma exclusiva, ausente da pressão competitiva dos genéricos. As consequências da prática descrita recaem sobre os consumidores, sejam eles diretos ou indiretos (como o governo), que necessitam arcar com os custos de medicamentos sobrevalorizados, resultantes de um monopólio supostamente ilícito. A FTC estima que a conduta custou 3,5 bilhões por ano ${ }^{3}$, de 2001 a 2015, para o consumidor americano.

O declínio na inovação, diversidade e competição do setor farmacêutico, identificado pela Federal Trade Commission, que despertou a atenção da autoridade para o potencial lesivo de tais acordos, que, até então, não eram analisados à luz do Direito Antitruste.

O quadro regulatório dos EUA foi um fator determinante para impulsionar as farmacêuticas a celebrarem acordos patentários com pagamento reverso, em contramão ao seu real objetivo. A lei conhecida como Hatch-Waxman Act criou um período de exclusividade de 180 dias para o primeiro medicamento genérico aprovado pela $\mathrm{FDA}^{4}$ para ser comercializado. O espírito desta previsão legal era incentivar a inovação, a diversidade

FEDERAL TRADE COMMISSION. Pay-for-Delay: How Drug Company Pay-Offs Cost Consumers Billions. Washington, DC: FTC, 2010, p. 8-10. Disponível em: <https://www.ftc.gov/sites/default/ files/documents/reports/pay-delay-how-drug-company-pay-offs-cost-consumers-billions-federal-tradecommission-staff-study/100112payfordelayrpt.pdf $>$. Acesso em: 25 nov. 2019.

4 Food and Drug Administration (FDA) - autoridade Estadunidense responsável pela autorização da comercialização de medicamentos, equivale à agência de vigilância sanitária brasileira - a ANVISA. 
e principalmente a entrada mais rápida de genéricos no mercado, com vistas a contribuir para a ampliação do acesso a medicamentos pela população.

No entanto, não são todos os 'primeiros genéricos' que fazem jus a tal direito exclusivo. Explica-se: no processo de aprovação do medicamento genérico, a farmacêutica depositante deve preencher um certificado indicando umas das quatro hipóteses, em relação ao seu medicamento referência, são elas: (i) não há patente do medicamento original; (ii) a patente já está em domínio público; (iii) a depositante se compromete a não introduzir o genérico no mercado enquanto a patente estiver vigente; (iv) o genérico entrante não infringe a patente ora vigente ou, então, a patente referência é inválida. Apenas na hipótese (iv) a farmacêutica é contemplada pelo período de 180 dias de exclusividade.

Após a submissão do certificado, a farmacêutica do medicamento referência é notificada sobre a hipótese submetida e tem 30 dias para, querendo, se manifestar sobre ela. Não raramente, a notificação da hipótese quatro motiva a farmacêutica detentora da patente a iniciar uma ação patentária para proteger seus supostos direitos. E, assim, se iniciam grandes litígios de patentes.

Cumpre salientar que, no início das investigações, muitas controvérsias sugiram entre as autoridades competentes que julgavam os litígios, tendo em vista, principalmente, o direito de propriedade intelectual envolvido nos casos - a patente, que, por sua natureza, confere um direito de exclusividade capaz de afastar a concorrência do objeto protegido e, por isso, foram proferidas decisões que blindavam o acordo das análises antitruste.

Foi apenas em 2013, com o leading case FTC v. Actavis, que a Suprema Corte dos Estados Unidos sedimentou o entendimento de que os acordos pay-for-delay podem, sim, violar as leis antitruste, devendo se sujeitar ao crivo das autoridades antitruste. O caso é, portanto, considerado um marco concorrencial.

Apesar do avanço trazido pelo leading case Actavis, muitos questionamentos ainda permaneceram em aberto, cita-se, como exemplo, o conceito de pagamento, ou seja, somente as contraprestações pecuniárias se enquadrariam como tal ou outras modalidades também? A questão é bastante relevante, pois o pagamento reverso é elementar para a configuração da conduta como pay-for-delay.

Um entendimento pacífico sobre o questionamento acima se tornou ainda mais importante na medida em que as farmacêuticas passaram a criar novas formas de compensar as empresas de genéricos, de modo a camuflar o pagamento reverso. As novas 
modalidades de pagamento, então, fazem parte de uma estratégia mais ampla das farmacêuticas para maquiar seus verdadeiros objetivos anticompetitivos.

Este novo cenário não foi capturado pela decisão da Suprema Corte dos Estados Unidos ao julgar o caso Actavis, que não definiu de maneira clara o conceito de pagamento reverso, causando divergência de entendimento quando o acordo envolve contraprestações não pecuniárias, como ocorre em algumas modalidades abaixo identificadas:

(i) cláusulas contratuais de no-AG (no-Authorized Generic), pelas quais as farmacêuticas do medicamento referência, que são as únicas autorizadas a comercializar a versão genérica de seu medicamento durante o período de exclusividade concedido ao primeiro genérico que entra no mercado nos termos da lei Hatch-Waxman Act., se comprometem a não entrar no mercado com seus genéricos autorizados durante tal período; em contraprestação, as empresas de genéricos podem atrasar por anos sua entrada no mercado;

(ii) cláusulas conhecidas como non-challenge clause, pelas quais as empresas de genéricos se comprometem a não protestar a validade de certa patente;

(iii) cláusulas "side-deals", as quais estabelecem serviços não relacionados, tais como de marketing, distribuição de produtos, fornecimento de insumos, prestados pela empresa de genérico; o pagamento reverso é, então, feito a título de pagamentos por serviços side-deals;

(iv) cláusulas de "poison-pills", que estabelecem que, se um outro genérico estiver prestes a receber autorização para entrar no mercado, o genérico parte do acordo patentário tem permissão para entrar imediatamente no mercado, de modo a desfrutar do período de exclusividade;

(v) cláusulas que preveem que a farmacêutica de marca não cobrará nenhum dano devido pela empresa de genérico, caso haja alguma decisão proferida judicialmente em desfavor da mesma.

Paralelamente aos Estados Unidos, a Comissão Europeia também vem direcionando especial atenção a tais acordos quando, em 2008, lançou uma investigação no setor farmacêutico, por identificar uma aparente falta de concorrência no mercado de medicamentos europeu. Os principais indícios de que o mercado farmacêutico não estava funcionando de forma plena foram: (i) os atrasos registrados na entrada de medicamentos genéricos e (ii) o declínio na inovação, constatado através do baixo número de novos medicamentos lançados. 
O leading case europeu é o caso Lundbeck, no qual a Comissão também concluiu haver responsabilidade antitruste sempre que o acordo celebrado envolver (i) concorrentes ou potenciais concorrentes, (ii) pagamento reverso e (iii) restrição à concorrência.

Não obstante, há uma discordância entre os padrões de provas e a metodologia de análise de ambos os casos - Lundbeck e Actavis. Como será visto no decorrer deste trabalho, a Comissão Europeia tende a considerar a conduta como ilícita pelo objeto, afastando a análise de efeitos no mercado, enquanto a FTC tende a adotar a regra da razão, aceitando algumas justificativas para a existência dos acordos.

Por fim, mas não menos importante, será a vez de endereçar as questões do cenário brasileiro através de um estudo comparado das análises engendradas pelas autoridades estrangeiras bem como da jurisprudência do CADE e legislação doméstica, com vistas a dialogar com as conclusões e metodologias estrangeiras levando em consideração as peculiaridades do sistema jurídico brasileiro.

Ao desenvolver sobre o tema dos acordos pay-for-delay, é inevitável não abordar sobre a aparente tensão existente entre o direito de propriedade intelectual e o direito antitruste, bem como a dinâmica peculiar do mercado farmacêutico que, por sua vez, encontra na proteção intelectual o grande impulsionador de suas atividades inventivas responsáveis por gerar inovação.

Partindo-se de uma perspectiva schumpeteriana, mostra-se precípuo o papel efetivo da inovação como motor pelo qual o agente econômico se sobressairá em relação aos seus competidores, promovendo a inovação econômica e tecnológica e alterando consideravelmente as condições prévias de equilíbrio de mercado. A inovação tecnológica exerce, portanto, cada vez mais, um atrativo fundamental na perspectiva do agente econômico.

É nesse cenário que se insere a importância da propriedade intelectual no campo da inovação, esta muitas vezes protegida por aquela, bem como a sua intersecção com o direito concorrencial e propriamente com a economia atual. Não por acaso que o teórico acima citado representa marco basilar que sustenta a razão de ser da propriedade industrial.

Não obstante, o direito de propriedade intelectual, bem como seu exercício, não estão imunes à aplicação do Direito Antitruste. No emblemático caso ANFAPE, foi unânime entre os Conselheiros o entendimento sobre a competência do CADE para julgar 
o exercício abusivo (Lei 12.529/11, art.36, $\S 3^{\circ}, \mathrm{XIX}^{5}$ ) e inadequado dos direitos industriais.

Importante frisar que o CADE ainda não analisou acordos pay-for-delay na indústria farmacêutica. Não estranhamente. Explica-se.

Tais acordos decorrem de um conflito, no qual uma empresa de medicamentos genéricos questiona a validade de uma patente farmacêutica. Contudo, até 1996 - quando a Lei de Propriedade Industrial (LPI) foi promulgada -, medicamentos não podiam ser objetos de patentes no Brasil, além de que a lei que estabeleceu os medicamentos genéricos $^{6}$ apenas entrou em vigor em 1999, datas em que as patentes nos EUA já vigoravam há muito tempo, bem como as leis sobre genéricos - jurisdição onde o propício cenário regulatório foi determinante para o seu pioneirismo na identificação e investigação de tais acordos.

Considerando que (i) o tempo médio de duração do processo para concessão de uma patente farmacêutica no Brasil é 13,5 $\operatorname{anos}^{7}$; e (ii) os primeiros depósitos de pedidos de patente se deram aproximadamente em 1996, conclui-se que as primeiras patentes farmacêuticas concedidas no Brasil, guardadas exceções, foram aproximadamente em 2009, vigentes até aproximadamente 2019. ${ }^{8}$ Considerando, ainda, que a maioria dos conflitos inicia-se perto da data de expiração da patente, resta evidente que o cenário brasileiro de propriedade industrial no mercado farmacêutico não incentivou a ocorrência da prática dos acordos pay-for-delay.

Contudo, ressalta-se que, atualmente, após a promulgação da LPI e da Lei dos Genéricos e com as concessões de patentes farmacêuticas no território brasileiro, o cenário doméstico vem se alterando substancialmente e se tornando mais propício para a prática.

5 “Art. 36. Constituem infração da ordem econômica, independentemente de culpa, os atos sob qualquer forma manifestados, que tenham por objeto ou possam produzir os seguintes efeitos, ainda que não sejam alcançados:

$[\ldots]$

XIX - exercer ou explorar abusivamente direitos de propriedade industrial, intelectual, tecnologia ou marca" (grifos nossos).

6 Lei no 9.787/1999, conhecida como Lei dos Genéricos.

7 INPI. Relatório de atividades 2017. Brasília: INPI, 2017, p. 19. Disponível em: $<$ http://www.inpi.gov.br/sobre/arquivos/relatorio-de-atividades-inpi-2017-versao-portugues.pdf $>$. Acesso em: 25 nov. 2019; INPI. Relatório de atividades 2018: dados preliminares. Brasília: INPI, 2018, p. 21. Disponível em: <http://www.inpi.gov.br/sobre/arquivos/relatorio-de-atividades-inpi-2018.pdf $>$. Acesso em: 25 nov. 2019.

${ }^{8}$ Apesar da duração da patente ser de 20 anos, quando o processo de concessão extrapola 10 anos, o seu titular se beneficiará de uma exclusividade de 10 anos. Art. 40, Parágrafo único. O prazo de vigência não será inferior a 10 (dez) anos para a patente de invenção e a 7 (sete) anos para a patente de modelo de utilidade, a contar da data de concessão, ressalvada a hipótese de o INPI estar impedido de proceder ao exame de mérito do pedido, por pendência judicial comprovada ou por motivo de força maior. 
Não obstante, o CADE analisou um caso de acordo pay-for-delay, porém fora do mercado farmacêutico; foi o caso Ediouro, no qual foram investigados, entre outras condutas, acordos pay-for-delay no mercado de revistas de divertimento, precedente que será amplamente analisado neste trabalho, além de casos emblemáticos analisados pelo CADE envolvendo patentes farmacêuticas, ainda que tenham outras condutas como objeto de análise.

Oportuno pontuar que, muito embora os acordos pay-for-delay analisados neste trabalho não tenham sido celebrados em território brasileiro, a teoria dos efeitos, da qual o Brasil é adepto, prevê a aplicação extraterritorial da jurisdição brasileira em matéria antitruste quando a prática produz ou possa vir a produzir efeitos no território nacional, conforme consagrado no artigo $2^{\circ}$ da Lei Antitruste brasileira. ${ }^{9}$

Neste sentido, verificou-se que muitos dos medicamentos parte dos acordos julgados anticompetitivos por nações estrangeiras, as quais sancionaram as farmacêuticas envolvidas, entraram no Brasil por meio de importação, conforme registro na ANVISA, recebendo autorização para serem comercializados em território nacional. Foi possível concluir, a partir de informações prestadas pela autoridade sanitária, que, em alguns casos, o medicamento entrou no Brasil durante o período da conduta, ou seja, quando os acordos ainda estavam vigentes.

No mais, importante mencionar que, de fato, uma das principais variáveis que determinam o preço do medicamento no Brasil é aquela praticada no país de origem, conforme Resolução nº 2/2004 da CMED.

Cumpre relembrar que os acordos pay-for-delay, a partir de uma análise sob a regra da razão, podem ser considerados ilícitos nos EUA, por violar as normas antitruste, nos termos da Seção 1 do Sherman Act. ${ }^{10}$ Os acordos também são considerados ilícitos pelo objeto, nos termos do artigo 101, n ${ }^{0}$ 1, do TFEU ${ }^{11}$, pela Comissão Europeia, quando presentes, cumulativamente, os três seguintes requisitos: (i) as partes envolvidas são concorrentes ou potenciais concorrentes; (ii) previsão de pagamento reverso; e

\footnotetext{
${ }^{9}$ Art. $2^{\circ}$ Aplica-se esta Lei, sem prejuízo de convenções e tratados de que seja signatário o Brasil, às práticas cometidas no todo ou em parte no território nacional ou que nele produzam ou possam produzir efeitos.

${ }^{10}$ Seção 1 do Sherman Act (Lei Antitruste dos EUA), 15 U.S. Code $\S 1^{\circ}$ "Every contract, combination in the form of trust or otherwise, or conspiracy, in restraint of trade or commerce among the several States, or with foreign nations, is declared to be illegal".

11 Tratado sobre o Funcionamento da União Europeia (TFEU), art. 101 (1): São incompatíveis com o mercado interno e proibidos todos os acordos entre empresas, todas as decisões de associações de empresas e todas as práticas concertadas que sejam susceptíveis de afetar o comércio entre os EstadosMembros e que tenham por objetivo ou efeito impedir, restringir ou falsear a concorrência no mercado interno (...).
} 
(iii) restrição à concorrência. Contudo, é de suma importância que se estabeleça como se dá o enquadramento dos acordos na legislação antitruste brasileira, mais especificamente, sua incidência nas hipóteses de infração à ordem econômica previstas em seu artigo 36. E, ainda mais importante, definir qual seria a metodologia e o padrão de provas adotados na análise da conduta.

Neste contexto, utilizando-se das investigações e conclusões das autoridades citadas no parágrafo anterior, foi realizado um estudo comparado para, então, adaptando-as ao arcabouço jurisprudencial e normativo brasileiro, construir uma análise própria, agregando elementos estrangeiros e domésticos.

Além do controle repressivo, o qual impõe investigação da conduta a posteriori, ou seja, após a concretização dos danos causados aos consumidores e à saúde pública e considerando, ainda, a alteração na estrutura natural da oferta devido à prática, propõe-se o controle preventivo de tais acordos a partir de sua notificação prévia por configurar ato de concentração nos termos do artigo 90, inciso IV - hipótese de contratos associativos - da lei 12.529/11.

Posto isso, com vistas ao pleno desenvolvimento dos temas acima expostos, o presente trabalho foi subdividido em 4 capítulos-chaves, além dos capítulos introdutório e conclusivo, essenciais para o amplo entendimento do debate.

O primeiro capítulo tratará dos traços principais das áreas do Direito de Propriedade Intelectual e do Direito Concorrencial, bem como da interface entre ambos. De modo a agregar e subsidiar os debates vindouros, o capítulo inicial abordará, também, as peculiaridades do setor farmacêutico, assim como as estratégias desenvolvidas pelas farmacêuticas e investigadas pelas autoridades competentes. Após o desenvolvimento dos temas fundamentais acima citados, será apresentada a conduta objeto de estudo deste trabalho - os acordos pay-for-delay.

O segundo capítulo se destinará ao estudo comparado dos acordos pay-for-delay na jurisdição estadunidense, principalmente no que tange ao desencadeamento das investigações, assim como seu desenvolvimento e as conclusões das autoridades judiciais e administrativas sobre a conduta. Serão endereçados, também, os questionamentos que ainda hoje permanecem em aberto, além do entendimento dos estudiosos do assunto sobre tais temas controversos.

Semelhantemente ao segundo capítulo, o capítulo três endereçará o estudo comparado dos acordos pay-for-delay segundo análise da Comissão Europeia. O desenvolvimento do capítulo trará os motivos que levaram a instauração de investigações 
setoriais na indústria farmacêutica, bem como seus desdobramentos e as conclusões tanto da Comissão Europeia como da Corte de Justiça Europeia, que julgou leading cases europeus envolvendo acordos pay-for-delay após apelação, pelas partes envolvidas, da decisão da Comissão. Por fim, mas não menos importante, será traçada uma análise crítica sobre os pontos comuns e distintos das decisões proferidas nas jurisdições comunitária e estadunidense.

O capítulo de fechamento abordará o cenário brasileiro. A construção de uma análise crítica nacional sobre os acordos contará com o estudo comparado das jurisdições estrangeiras, bem como com o sistema jurídico doméstico, principalmente em relação à jurisprudência do CADE e à legislação antitruste brasileira, além das contribuições das experiências da ANVISA e INPI. 


\section{CONCLUSÃO}

Como visto ao longo desta dissertação, acordos homologados no âmbito judicial podem dar ensejo à responsabilidade antitruste quando tratarem de matéria concorrencialmente sensível ou por implicarem, ainda que potencialmente, em efeitos lesivos à concorrência. No mesmo sentido, o exercício de direitos de propriedade industrial não está imune à aplicação do Direito Antitruste pela autoridade competente.

Os acordos pay-for-delay, por sua vez, são acordos que envolvem direitos patentários, celebrados tanto no no âmbito judicial como de forma extrajudicial. Grande parte desses acordos preveem cláusulas que resultam em restrição indevida à concorrência; não por outra razão, tais acordos devem se sujeitar ao escrutínio antitruste. Esse é o entendimento compartilhado por autoridades de defesa da concorrência, tais como o CADE, a Comissão Europeia e a Federal Trade Commission, ainda que elas divirjam quanto à metodologia de análise aplicada aos casos.

A Comissão Europeia, no leading case Lundbeck, optou por aplicar a ilicitude pelo objeto sempre que o acordo envolver: (i) partes concorrentes ou potencialmente concorrentes; (ii) pagamento reverso; e (iii) previsão de restrição à concorrência. Em sua decisão, a Comissão entendeu que os acordos foram firmados em violação ao artigo 101 (1) do TFUE. ${ }^{536}$

Já a Suprema Corte dos EUA adotou, na decisão do leading case Actavis, a regra da razão como método de análise dos acordos pay-for-delay, admitindo como possíveis justificativas (i) a magnitude do pagamento, ou seja, se o valor for semelhante aos custos esperados no litígio patentário, não haveria preocupação antitruste, pois a suposta intenção por trás do uso do pagamento seria a solução do conflito, evitando os longos e desgastantes litígios; e (ii) os serviços side-deals, ou seja, pagamentos efetuados mediante prestação de serviços da empresa de genéricos para a de marca, tais como a venda de matéria-prima, distribuição de medicamentos, marketing. Ressalta-se que a FTC constatou, em suas investigações, que grande parte dos acordos com side-deals estão dentro de acordos payfor-delay e que as empresas de marca padecem de interesse em relação aos serviços das empresas de genéricos, preferindo contratar outras empresas de medicamentos de marca,

\footnotetext{
${ }^{536}$ Tratado sobre o Funcionamento da União Europeia (TFEU), art. 101 “(1): São incompatíveis com o mercado interno e proibidos todos os acordos entre empresas, todas as decisões de associações de empresas e todas as práticas concertadas que sejam susceptíveis de afetar o comércio entre os EstadosMembros e que tenham por objetivo ou efeito impedir, restringir ou falsear a concorrência no mercado interno $[\ldots]$. ."
} 
caso precisem de algum serviço, levando a FTC a concluir que a intenção por trás dos serviços side-deals é, na maioria das vezes, anticompetitiva.

A decisão Actavis é concorrencialmente bastante relevante, pois solucionou as divergências entre as cortes de apelação ao sedimentar que os acordos pay-for-delay se sujeitando, sim, a análise antitruste, pois podem violar os termos da Seção 1 do Sherman Act. $^{537}$

O CADE ainda não analisou acordos pay-for-delay no mercado farmacêutico, contudo o cenário brasileiro, por muito tempo, não foi propício à prática, principalmente, devido às tardias legislações de propriedade industrial aplicáveis ao setor de fármacos, promulgadas apenas após as obrigações impostas pelo acordo TRIPS e aos baixos investimentos em P\&D, fase essencial para o desenvolvimento de medicamentos protegidos por PI - o que, na realidade, justifica a falta de incentivos para criar leis de proteção industrial. Cumpre ressaltar, no entanto, que o cenário brasileiro vem se alterando substancialmente desde a promulgação da LPI e da Lei de Genéricos.

Cumpre ressaltar que o Brasil, assim como muitas outras jurisdições, adotou expressamente em sua legislação a teoria dos efeitos, a qual prevê a aplicação extraterritorial da jurisdição brasileira em matéria antitruste quando a prática produz ou possa produzir efeitos no território nacional. Tal previsão se revela fundamental na atual economia global, na qual as práticas dos Estados transcendem suas fronteiras e, não raramente, impactam negativamente no mercado de outros Estados.

As pesquisas realizadas no site da ANVISA e informações prestadas pela autoridade revelaram que muitos dos medicamentos objeto de acordos julgados anticompetitivos por autoridades estrangeiras foram registrados pela autoridade sanitária brasileira, recebendo autorização para serem comercializados no Brasil durante o período em que a conduta ainda não havia cessado e, portanto, ao menos potencialmente, tais medicamentos poderiam entrar no território nacional através de importação. Ressalto que o registro na ANVISA, além da autorização para o comércio, significa a intenção da empresa em vender seus medicamentos no Brasil.

Considerando que (i) a jurisdição antitruste brasileira alcança tanto os efeitos concretos como os potenciais e, (ii) a partir do registro na ANVISA, o medicamento já está potencialmente apto para penetrar no mercado brasileiro, resta evidente a competência do

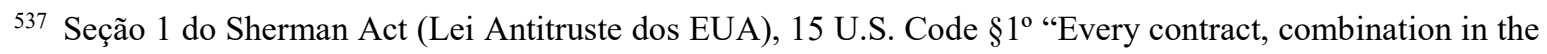
form of trust or otherwise, or conspiracy, in restraint of trade or commerce among the several States, or with foreign nations, is declared to be illegal". 
CADE para investigar, julgar e sancionar as farmacêuticas pela celebração de acordos payfor-delay que tenham como objeto medicamentos importados pelo Brasil ou ao menos registrados (ainda que não importados) durante a vigência do acordo.

Os acordos pay-for-delay podem configurar infração à ordem econômica à luz da legislação antitruste brasileira, sendo, assim, passíveis de enquadramento nos incisos III e IV do $\S 3^{\circ}$ do artigo 36, combinado com o inciso I do mesmo artigo da Lei 12.529/2011.

Quanto à análise da possível configuração de infração à ordem econômica, concluiu-se que os acordos serão considerados ilícitos pelo objeto quando apresentarem os três elementos 'mínimos', que são aqueles estabelecidos na decisão da Comissão: (i) concorrência ou potencial concorrência entre as partes contratantes; (ii) previsão de pagamento reverso; e (iii) restrição à concorrência, os quais devem ser somados a um dos elementos a seguir, conforme depreendido do caso Ediouro: (i) a patente envolvida já se encontra em domínio público; (ii) a previsão da restrição vai além da data de vigência da patente; ou (iii) a restrição estabelecida é por prazo indeterminado.

Caso o acordo não apresente nenhum dos elementos adicionais, ou seja, a patente é vigente, a obrigação tem prazo determinado e se insere dentro do prazo de vigência da patente; semelhantemente ao que ocorre no Patent-Term Split Agreement, o acordo poderá ser analisado pelo CADE por meio do método quick look. Ou seja, a conduta será presumida ilícita, porém, no caso remoto de a farmacêutica representada lograr em demonstrar algum efeito pró-competitivo decorrente do acordo, o representante (que poderá ser o CADE, em casos instaurados ex officio) deverá, então, demonstrar que os efeitos restritivos do acordo superam aquele pró-competitivo demonstrado pela representada. De acordo com a Federal Trade Commission e a Suprema Corte dos EUA, se o Patent-Term Split Agreement não envolver pagamento pecuniário, ele poderá ser considerado lícito, pois, neste caso, as farmacêuticas estariam estabelecendo uma data de entrada do genérico ainda na vigência da patente, segundo a crença das partes sobre a força da patente envolvida.

Vale ressaltar que a ANVISA e o INPI, dentro de seu âmbito de competência, podem contribuir para o combate a práticas que utilizam o direito de propriedade industrial como instrumento para concreção de condutas anticompetitivas. As patentes denominadas 'fracas', isto é, aquelas concedidas mediante vícios e irregularidades, por não cumprirem os requisitos legais de patenteabilidade, são os principais objetos de acordos pay-for-delay, pois eles funcionam como uma camada extra de proteção para patentes que sabidamente não merecem proteção dos direitos industriais. Portanto, um enrijecimento dos exames 
para obtenção de patentes bem como o trato minucioso dos documentos submetidos pelas farmacêuticas são fundamentais para que patentes não sejam concedidas irregularmente e se tornem objeto de práticas anticompetitivas. Conforme constatado pela Federal Trade Commission e Comissão Europeia, as patentes secundárias, também conhecidas como patentes de melhoria, e as patentes de processo são as mais propícias a serem objetos de condutas anticompetitivas, devendo, assim, ter um rigor maior em sua análise.

Os acordos pay-for-delay vem sendo analisados pelas autoridades de defesa da concorrência através do controle de conduta, ou seja, após a identificação e concreção dos danos causados ao mercado e à concorrência. Contudo, é de extrema importância o tratamento preventivo de tais acordos, pois eles envolvem matéria concorrencialmente sensível e impactam diretamente na saúde pública, restringindo o acesso da população a medicamentos. No mais, os acordos pay-for-delay, diferentemente de outras condutas coordenadas, são concretizados a partir de instrumentos formais. Resta evidente, portanto, que os acordos pay-for-delay demandam um controle a priori, para que ele possa ser executado apenas após análise e autorização da autoridade antitruste competente, para que sua lesividade não alcance os consumidores, ainda que sua aprovação esteja condicionada à supressão das cláusulas restritivas.

Verificou-se que a hipótese mais adequada para o enquadramento dos acordos pay-for-delay como ato de concentração é o contrato associativo, previsto no inciso IV do artigo 90 da Lei 12.529/11. Contudo, os acordos pay-for-delay não se enquadram nos termos da atual norma que disciplina os contratos associativos, a Resolução no 17/2016, por não estabelecerem empreendimento em comum para exploração de atividade econômica, conforme previsto no caput do artigo $2^{\circ}$ da resolução mencionada.

Cumpre ressaltar, no entanto, que o CADE, ao analisar contratos associativos, demonstrou substancial preocupação nas hipóteses em que tais acordos eram firmados entre concorrentes e estabeleciam cláusulas restritivas ou resultavam em alterações na oferta de certo produto ou serviço no mercado. Frisa-se que os acordos pay-for-delay preveem cláusulas que impõem restrições a concorrentes, afastando-os do mercado, consequentemente altera-se a oferta que se teria caso ausente a conduta, principalmente no que tange a sua diversidade e preço.

Portanto, ainda que os clássicos acordos pay for delay não se enquadrem na letra expressa da Resolução $n^{0}$ 17/2016, por não estabelecerem empreendimento em comum, a sensibilidade do seu conteúdo demanda a análise prévia da autoridade antitruste. 
Diante do exposto, sugere-se uma nova redação ao atual artigo $2^{\circ}$ da Resolução $n^{\circ}$ 17/2016 para que os acordos pay-for-delay sejam enquadrados como contrato associativo:

Art. $2^{\circ}$ Considera-se associativos quaisquer contratos com duração igual ou superior a 2 (dois) anos em que as partes contratantes sejam concorrentes ou potencialmente concorrentes no mercado relevante objeto do contrato, desde que:

I - o contrato estabeleça empreendimento comum para exploração de atividade econômica com o compartilhamento de riscos e resultados; ou II - o contrato estabeleça disposição restritiva à concorrência. 


\section{REFERÊNCIAS}

ABA. Intellectual Property and Antitrust Handbook. Chicago, IL: American Bar Association/Section of Antitrust Law, 2007.

AMERICAN BAR ASSOCIATION (ABA). Antitrust Law Developments (Sixth). Chicago: ABA/ Section of Antitrust Law, 2007.

AMERICAN INTELLECTUAL PROPERTY LAW ASSOCIATION (AIPLA). Request for Public Comments: Development of the Joint Strategic Plan on Intellectual Property Enforcement 80 Fed. Reg. 52800 (September 1, 2015). Washington, DC: Aipla, 30 Oct. 2015. Disponível em: https://www.aipla.org/docs/defaultsource/advocacy/documents/aipla-letter-on-ipec-joint-strategic-plan-10-30-15.pdf>. Acesso em: 01 jun. 2018.

AMORIM, Fernando. A ilicitude pelo objeto e o alcance da discricionariedade do CADE no processo administrativo sancionador antitruste. Revista de Defesa da Concorrência (RDC), v. 5, n. 2, p. 75-102, nov. 2017.

ANVISA. Anvisa e INPI: acordo acelera análise de patentes. Brasília: Anvisa, 12 abr. 2017. Disponível em: $<$ http://portal.anvisa.gov.br/noticias//asset_publisher/FXrpx9qY7FbU/content/anvisa-e-inpi-acordo-acelera-analise-depatentes/219201/pop_up?_101_INSTANCE_FXrpx9qY7FbU_viewMode=print\&_101_IN STANCE_FXrpx9qY7FbU_languageId=pt_BR >. Acesso em: 12 abr. 2019.

. COOPI/GGMED. Relatório de patentes. Em resposta ao ofício 18/2016 (SEI $\overline{0225737)}$ enviado pelo CADE no âmbito do Inquérito Administrativo $\mathrm{n}^{\mathrm{o}}$ 080120011615/2008-08. Brasília: Anvisa, 15 jul. 2016.

ASCARELLI, Túlio. Teoria della concorrenza e dei beni immateriali: istituzioni di diritto industriale. 3. ed. Milano: Dott. A. Giuffrè, 1960.

ATHAYDE, Amanda. Antitruste, varejo e infrações à ordem econômica. São Paulo: Singular, 2017.

ATIYAH, Patrick S. An introduction to the law of contract. 4. ed. Oxford: Clarendon Press, 1989.

Freedom of contract and the new right. In: . Essays on contract. Oxford: Clarendon Press, 2001. p. 355-358.

The rise and fall of freedom of contract. Oxford: Clarendon Press, 1979.

AVILA, Jorge de Paula Costa. Propriedade Intelectual, Inovação farmacêutica, Acesso a Medicamentos e as Patentes do "Pipeline". Apresentação no INPI. Brasília, 28 nov. 2007.

AZEVEDO, Paulo Furquim de. Contratos: uma perspectiva econômica. In: Décio ZYLBERSZTAJN; Rachel SZTAJN. Direito e economia: análise econômica do direito e das organizações. Rio de Janeiro: Elsevier, 2005. 
BEERS, Donald O.; KARST, Kurt R. Generic And Innovator Drugs: A Guide To FDA Approval Requirements. 8. ed. New York: Wolters Kluwer, 2013.

BESCHLE, Donald L. What, Never? Well, Hardly Ever: Strict Antitrust Scrutiny as an Alternative to Per se Antitrust Illegality. Hastings Law Journal, v. 38, n. 3, p. 471-515, 1987.

BOLDRIN, Michele; LEVINE, David K. The case against Patents. Journal of Economic perspectives, v. 27, n. 1, p. 3-22, Winter 2013. Disponível em:

$<$ https://www.aeaweb.org/articles?id=10.1257/jep.27.1.3>. Acesso em: 26 maio 2018.

BRUNA, Sérgio Varella. O poder econômico e a conceituação do abuso em seu exercício. São Paulo: Revista dos Tribunais, 2001.

BURINI, Bruno Corrêa. Processo administrativo de apuração de conduta anticoncorrencial: perspectiva instrumentalista. 2010. Tese (Doutorado em Direito) Faculdade de Direito, Universidade de São Paulo, São Paulo, 2010.

CADE. Balanço de Gestão Superintendência-Geral 2014 a 2017. Atos de Concentração. Brasília: CADE, jun. 2017. Disponível em:

$<$ http://www.cade.gov.br/servicos/imprensa/balancos-e-apresentacoes/balanco-mandatosg-2014-2017.pdf>. Acesso em: 19 jun. 2019.

. Termo Aditivo ao Acordo de Cooperação Técnica no 02/2013. PROCESSO no 08700.001628/2013-70. Termo aditivo a acordo de cooperação técnica que entre si celebram a Conselho Administrativo de Defesa Econômica e a Agência Nacional de Vigilância Sanitária - (Anvisa), para os fins que especifica. Brasília, 24 jan. 2019.

Disponível em:

$<$ https://sei.cade.gov.br/sei/publicacoes/controlador_publicacoes.php?acao=publicacao_vis ualizar\&id_documento $=616365 \& i d \_$orgao_publicacao $=0>$. Acesso em: 9 out. 2019.

CALIFORNIA. Office of Governor. Governor Gavin Newsom Signs Legislation Banning "Pay for Delay" to Fight Runaway Prescription Drug Costs. Sacramento, 7 Oct. 2019. Disponível em: <https://www.gov.ca.gov/2019/10/07/governor-gavin-newsom-signslegislation-banning-pay-for-delay-to-fight-runaway-prescription-drug-costs/>. Acesso em: 20 out. 2019.

CARRIER, Michael A. Payment After Actavis. Iowa Law Review, v. 100, p. 7-49, 2014.

. Unsettling Drug Patent Settlements: A Framework for Presumptive Illegality, Michigan Law Review, v. 108, p. 37-80, 2009.

CARVALHO, Vinicius Marques de; RODRIGUES, Eduardo Frade. Guia para análise da consumação prévia de atos de concentração econômica. Brasília: CADE, maio 2015.

COMISSÃO EUROPEIA. Comunicação da Comissão. Síntese do Relatório sobre o Inquérito ao sector farmacêutico. Bruxelas: CE, 2009, p. 8-10. Disponível em: $<$ http://ec.europa.eu/competition/sectors/pharmaceuticals/inquiry/communication_pt.pdf $>$. Acesso em: 21 nov. 2018. 
sector pursuant to Article 17 of Council Regulation (EC) n $n^{0}$ 1/2003. Strasbourg, 15 Jan. 2008. Disponível em:

$<$ https://ec.europa.eu/competition/sectors/pharmaceuticals/inquiry/decision_en.pdf $>$. Acesso em: 03 jun. 2018.

CONGRESSIONAL BUDGET OFFICE. How Increased Competition From Generic Drugs Has Affected Prices And Returns In The Pharmaceutical Industry.

Washington, DC: CBO, Jul. 1998. Disponível em:

$<$ https://www.cbo.gov/sites/default/files/105th-congress-1997-1998/reports/pharm.pdf $>$. Acesso em: 9 jul. 2019.

COOTER, Robert; ULEN, Thomas. Direito \& Economia. 5. ed. Porto Alegre: Bookman, 2010.

COUGHLIN, Daniel F.; DEDE, Rochelle A.. Hatch-Waxman Game-Playing from a Generic Manufacturer Perspective: From Ticlid ${ }^{\circledR}$ to Pravachol ${ }^{\circledR}$, Apotex Has Difficulty Telling Who's on First. Biotechnology Law Report, v. 25, n. 5, p. 525-533, Oct. 2006.

CRANE, Daniel A. Exit Payments in Settlement of Patent Infringement Lawsuits:

Antitrust Rules and Economic Implications. Florida Law Review, v. 54, n. 4, p. 747-798, Sept. 2002.

DABBAH, Maher M. International and comparative competition law. Cambridge: University Press, 2010.

DEL NERO, Patrícia Aurélio. Propriedade Intelectual e Transferência de Tecnologia. Belo Horizonte: Fórum, 2011.

DI PIETRO, Maria Sylvia Zanella. O princípio da segurança jurídica diante do princípio da legalidade. In: MARRARA, Thiago (org.). Princípios de Direito Administrativo:

Legalidade, Segurança Jurídica, Impessoalidade, Publicidade, Motivação, Eficiência, Moralidade, Razoabilidade, Interesse Público. São Paulo: Atlas, 2012. p. 3-29.

DICKEY, Bret. An Economic Assessment Settlements in the Pharmaceutical Industry. Annals Health Law, v. 19, p. 367-389, 2010.

DOGAN, Stacey; LEMLEY, Mark. Antitrust Law and Regulatory Gaming. Texas Law Review, v. 87, p. 1-58, 2008.

ELHAUGE, Einer; KRUEGER, Alex. Solving the Patent Settlement Puzzle. Cambridge, MA: Harvard/ John M. Olin Center for Law, Economic, and Business, 2012.

\section{EUROPEAN COMMISSION. 8th Report on the Monitoring of Patent Settlements} (period: January-December 2016). Brussels: EC, 9 Mar. 2018. Disponível em: $<$ https://ec.europa.eu/competition/sectors/pharmaceuticals/inquiry/patent_settlements_repo rt8_en.pdf $>$. Acesso em: 05 Jun. 2018.

. Competition DG. Pharmaceutical Sector Inquiry: Final Report. Brussels: EC, 8 Jul. 2009. Disponível em:

$<$ https://ec.europa.eu/competition/sectors/pharmaceuticals/inquiry/staff_working_paper_pa rt1.pdf>. Acesso em: 25 nov. 2019. 
. Pharmaceutical Sector Inquiry. Preliminary Report. Brussels: EC, 28 Nov. 2008, p. 28. Disponível em:

$<$ https://ec.europa.eu/competition/sectors/pharmaceuticals/inquiry/preliminary_report.pdf $>$ . Acesso em: 07 jun. 2018.

\section{EUROPEAN FEDERATION OF PHARMACEUTICAL INDUSTRIES AND}

ASSOCIATIONS. The Pharmaceutical Industry in Figures. Brussels: EFPIA, 2006.

Disponível em:

$<$ https://christianengstrom.files.wordpress.com/2011/03/infigures2006.pdf $>$. Acesso em: 3 jun. 2018.

FARIA, Jaqueline Borges de. Licença compulsória para a garantia do acesso universal a anti-retrovirais no Brasil. Revista da Associação Brasileira da Propriedade Intelectual, v. 85 , p. 26-37, nov./dez. 2006.

FEDERAL TRADE COMMISSION. Agreements Filed with the Federal Trade Commission under the Medicare Prescription Drug, Improvement, and Modernization Act of 2003: Overview of Agreements Filed in FY 2015 - A Report by the Bureau of Competition. Washington, DC: FTC, Nov. 2017. Disponível em: $<$ https://www.ftc.gov/system/files/documents/reports/agreements-filed-federal-tradecommission-under-medicare-prescription-drug-improvementmodernization/overview_of_fy_2015_mma_agreements_0.pdf $>$. Acesso em: 18 out. 2018.

. Anticompetitive Patent Settlements in the Pharmaceutical Industry: The Benefits of a Legislative Solution (statement). Committee on the Judiciary of the United States Senate. Washington, DC: FTC, 17 Jan. 2007. Disponível em:

$<$ https://www.ftc.gov/sites/default/files/documents/public_statements/prepared-statementfederal-trade-commission-anticompetitive-patent-settlements-

pharmaceutical/070117anticompetitivepatentsettlements_senate.pdf $>$. Acesso em: 25 nov. 2019.

. Bureau of Competition. Overview of Agreements Filed in FY 2014.

Washington, DC: FTC, 2014. Disponível em:

$<$ https://www.ftc.gov/system/files/documents/reports/agreements-filled-federal-tradecommission-under-medicare-prescription-drug-improvement/160113mmafy14rpt.pdf $>$. Acesso em: 30 out. 2018.

. Endo Pharmaceuticals Inc. Agrees to Abandon Anticompetitive Pay-forDelay Agreements to Settle FTC Charges; FTC Refiles Suits Against Generic Defendants. Washington, DC: FTC, 23 Jan. 2017. Disponível no link: $<$ https://www.ftc.gov/news-events/press-releases/2017/01/endo-pharmaceuticals-incagrees-abandon-anticompetitive-pay-delay>. Acesso em: 9 out. 2018.

. FTC Chairman Members of Congress Call for Legislation to End Sweetheart Pay-for-Delay Deals That Keep Generic Drugs Off the Market. Washington, DC: FTC, 10 Jan. 2010. Disponível em: $<$ https://www.ftc.gov/news-events/pressreleases/2010/01/ftc-chairman-members-congress-call-legislation-end-sweetheart-pay>. Acesso em: 25 nov. 2019.

. FTC Files Amicus Brief Explaining That "No-AG" Agreements Are Used by Drug Companies to Delay Generic Competition. Washington, DC: FTC, 13 Aug. 2012. 
Disponível em: <https://www.ftc.gov/news-events/press-releases/2012/08/ftc-files-amicusbrief-explaining-no-ag-agreements-are-used-drug>. Acesso em: 6 Jul. 2019.

FTC Report Examines How Authorized Generics Affect the Pharmaceutical Market. Washington, DC: FTC, 31 Aug. 2011. Disponível em: $<$ https://www.ftc.gov/news-events/press-releases/2011/08/ftc-report-examines-howauthorized-generics-affect-pharmaceutical> . Acesso em: 6 Jul. 2019.

. FTC Report on Drug Patent Settlements Shows Potential Pay-for-Delay Deals Decreased Substantially in the First Year Since Supreme Court's Actavis Decision. Washington, DC: FTC, 13 Jan. 2016. Disponível em: $<$ https://www.ftc.gov/news-events/press-releases/2016/01/ftc-report-drug-patentsettlements-shows-potential-pay-delay>. Acesso em: 4 set. 2019.

FTC Submits Amicus Brief Explaining that Drug Companies Use NoAuthorized Generic Agreements to Delay Generic Competition. Washington, DC: FTC, 9 Oct. 2012. Disponível em: <https://www.ftc.gov/news-events/pressreleases/2012/10/ftc-submits-amicus-brief-explaining-drug-companies-use-no $>$. Acesso em: 6 Jul. 2019.

FTC Sues Cephalon, Inc. for Unlawfully Blocking Sale of Lower-Cost Generic Versions of Branded Drug Until 2012. Washington, DC: FTC, 13 Feb. 2008. Disponível em: $<$ https://www.ftc.gov/news-events/press-releases/2008/02/ftc-suescephalon-inc-unlawfully-blocking-sale-lower-cost-generic $>$. Acesso em: 6 Jul. 2019.

. FTC Testifies before House Judiciary Committee's Subcommittee on Regulatory Reform, Commercial and Antitrust Law about Antitrust Concerns and the FDA Approval Process. Washington, DC: FTC, 27 Jul. 2017. Disponível em: $<$ https://www.ftc.gov/news-events/press-releases/2017/07/ftc-testifies-house-judiciarycommittees-subcommittee-regulatory>. Acesso em: 24 nov. 2019..

FTC: Recent Supreme Court Decision Puts Agency in Stronger Position to Protect Consumers From Anticompetitive Pay-for-Delay Drug Settlements. Washington, DC: FTC, 23 Jul. 2013. Disponível em: <https://www.ftc.gov/news-events/pressreleases/2013/07/ftc-recent-supreme-court-decision-puts-agency-stronger-position $>$. Acesso em: 10 out. 2019.

Generic Drug Entry Prior to Patent Expiration: an FTC study. Washington, DC: FTC, July 2002. Disponível em:

$<$ https://www.ftc.gov/sites/default/files/documents/reports/generic-drug-entry-prior-patentexpiration-ftc-study/genericdrugstudy_0.pdf >. Acesso em: 25 nov. 2019.

. In re Lamictal Direct Purchaser Antitrust Litigation. No. 2:12-cv-995-WHWCLW. Washington, DC: FTC, 28 Apr. 2014. Disponível em: $<$ https://www.ftc.gov/system/files/documents/amicus_briefs/re-lamictal-direct-purchaserantitrust-litigation/140428lamictalbrief.pdf>. Acesso em: 07 jun. 2017.

. Issues Interim Report on "Authorized Generic" Drugs. Washington, DC: FTC, 24 Jun. 2009. Disponível em: $<$ https://www.ftc.gov/news-events/pressreleases/2009/06/ftc-issues-interim-report-authorized-generic-drugs $>$. Acesso em: 10 out. 2018 
. Pay-For-Delay Deals: Limiting Competition and Costing Consumers (statement). Before the United States Senate Committee on the Judiciary Subcommittee on Antitrust, Competition Policy and Consumer Rights. Washington, DC: FTC, 23 Jul. 2013.

Disponível em:

$<$ https://www.ftc.gov/sites/default/files/documents/public_statements/prepared-statementfederal-trade-commission-pay-delay-deals-limiting-competition-andcosting/130723payfordelay.pdf $>$. Acesso em: 20 out. 2019.

. Pay-for-Delay: How Drug Company Pay-Offs Cost Consumers Billions.

Washington, DC: FTC, 2010, p. 8-10. Disponível em:

$<$ https://www.ftc.gov/sites/default/files/documents/reports/pay-delay-how-drug-companypay-offs-cost-consumers-billions-federal-trade-commission-staffstudy/100112payfordelayrpt.pdf>. Acesso em: 25 nov. 2019.

FELDMAN, Robin. Rethinking Patent Law. Cambridge, MA: Harvard University Press, 2012.

FERRAZ JUNIOR, Tercio Sampaio. Introdução ao estudo do direito: técnica, decisão, dominação. 4. ed. São Paulo: Atlas, 2003.

. Propriedade industrial e defesa da concorrência. Revista da Associação

Brasileira da Propriedade Intelectual, São Paulo, v. 2, n. 8, p. 10-12, jul./out. 1993.

FOOD AND DRUG ADMINISTRATION. Center For Drug Evaluation And Research.

Generic Competition and Drug Prices. Silver Spring, MD: FDA, 13 Dec. 2019.

Disponível em: $<$ https:/www.fda.gov/about-fda/center-drug-evaluation-and-researchcder/generic-competition-and-drug-prices>. Acesso em: 10 nov. 2019.

. Code of Federal Regulation. Title 21, v. 5, Section 314.94 1st Apr. 2019, (a)

(12) (viii) (A). Disponível em:

$<$ https://www.accessdata.fda.gov/scripts/cdrh/cfdocs/cfcfr/cfrsearch.cfm? fr=314.94>.

Acesso em: 10 nov. 2019.

. FDA analysis of retail sales data from IMS Health. IMS National Sales

Perspective (TM), 1999-2004. Washington, DC, Feb. 2005.

FORGIONI, Paula. Os fundamentos do antitruste. 4. ed. rev., atual. e ampl. São Paulo:

Revista dos Tribunais, 2010.

FORMENTI, Lígia. Análise de pedidos de patentes de medicamentos deve ser retomada com acordo entre Anvisa e INPI. O Estado de S.Paulo - Economia \& Negócios, São Paulo, 12 abr. 2017. Disponível em:

$<$ https://economia.estadao.com.br/noticias/geral,analise-de-pedidos-de-medicamentosdeve-ser-retomada-com-acordo-entre-anvisa-e-inpi,70001736792>. Acesso em: $12 \mathrm{abr}$. 2019.

GOMES, Orlando. Contratos. 24. ed. Rio de Janeiro: Forense, 2001.

. Introdução ao Direito Civil. 19. ed. Rio de Janeiro: Lumen Juris, 2008. 
GONÇALVES, Priscila Brolio. A obrigatoriedade de contratar como sanção fundada no direito concorrencial brasileiro. Tese (Doutorado em Direito) - Universidade de São Paulo, São Paulo, 2008.

. Fixação e sugestão de preços de revenda em contratos de distribuição: análise dos aspectos concorrenciais. São Paulo: Singular, 2002.

GRAU, Eros Roberto; FORGIONI, Paula Andréa. Ainda um novo paradigma dos contratos? In: . O estado, a empresa e o contrato. São Paulo: Malheiros, 2005. p. 15-23.

GREENE, Stephanie. A prescription for Change: How the Medicare Act Revises HatchWaxman to Speed Market Entry of Generic Drugs. Journal of Corporation Law, v. 30, n. 2, p. 309-355, Winter 2005.

HARRIS, Gardiner. Prilosec's Mark Switches Users to Nexium, Thwarting Generics. Wall Street Journal, New York, 2 June 2002.

HAYDEN, Cori. No patent, no generic: pharmaceutical access and the politics of the copy. Chicago: The University of Chicago Press, 2011.

HELFER, Laurence R.; AUSTIN, Graeme W. Human Rights and Intellectual Property - Mapping the global Interface. Cambridge: Cambridge University Press, 2011.

HEMPHILL, Christopher Scott. An Aggregate Approach to Antitrust: Using New Data and Rulemaking to Preserve Drug Competition. Columbia Law Review, v. 109, n. 4, p. 629-688, May 2009.

; LEMLEY, Mark A. Earning Exclusivity: Generic Drug Incentives and the HatchWaxman Act. Antitrust Law Journal, v. 77, p. 947-989, 2011. $1387,2013$.

; SAMPT, Bhaven. Drug Patents at the Supreme Court. Science, v. 339, p. 1386-

HOVENKAMP, Herbert. Federal Antitrust Policy: The Law of Competition and its Practices. $3^{\text {rd }}$ ed. St. Paul, MN: Thomson West, 2005.

. The Harvard and Chicago Schools and the Dominant Firm. In: PITOFSKY, Robert (Org). How the Chicago School Overshot the Mark. Oxford: Oxford University Press, 2008. p. 108-122.

. The rule of Reason. Florida Law Review, University of Pennsylvania Law School, v. 70, p. 81-167, 2018.

; AREEDA, Phillip. Antitrust Law: An Analysis of Antitrust Principles and Their Application. $3^{\text {rd }}$. ed. New York: Walter Kluwer Law \& Business, 2012.

; JANIS, Mark D.; LEMLEY, Mark A.; LESLIE, Christopher R.; CARRIER, Michael A. IP and Antitrust: an Analysis of Antitrust Principles Applied to Intellectual Property Law. New York: Aspen Law \& Business, 2002. 
INPI. Relatório de atividades 2017. Brasília: INPI, 2017, p. 19. Disponível em: $<\mathrm{http}$ //www.inpi.gov.br/sobre/arquivos/relatorio-de-atividades-inpi-2017-versaoportugues.pdf $>$. Acesso em: 25 nov. 2019.

INPI. Relatório de atividades 2018: dados preliminares. Brasília: INPI, 2018, p. 21. Disponível em: $<$ http://www.inpi.gov.br/sobre/arquivos/relatorio-de-atividades-inpi2018.pdf $>$. Acesso em: 25 nov. 2019.

INTERFARMA. Associação da Indústria Farmacêutica de Pesquisa. INPI e ANVISA: os conflitos na avaliação de patentes de medicamentos estão próximos do fim. São Paulo: Interfarma, 3 abr. 2017.

INTERNATIONAL COMPETITION NETWORK. Recommended Practices for Merger Notification and Review Procedures. Working Group Comments. ICN, Sept. 2002, amended: May 2017. p. 6. Disponível em:

$<$ https://www.internationalcompetitionnetwork.org/wpcontent/uploads/2018/09/MWG_NPRecPractices2018.pdf>. Acesso em: 19 jun. 2019).

JAEGER JUNIOR, Augusto. Direito internacional da concorrência: entre perspectivas unilaterais, multilaterais, bilaterais e regionais. Curitiba: Juruá, 2008.

JAFFE, Adam B.; LERNER, Josh. Innovation and its discontents: How our broken patent system is endangering innovation and progress, and what to do about it. Princeton, NJ: Princeton University Press, 2011.

JANICKE, Paul M.; REN, LiLan. Who wins patent infringement cases. AIPLA Quartely Journal, v. 34, n. 1, p. 18-20, Winter 2006. Disponível em:

$<$ http://licensinglaw.net/Litigation_files/Paul_M_Janicke.pdf $>$. Acesso em: 25 nov. 2019.

JORGE, Mariana Sebalhos. Teoria dos Efeitos no Direito Concorrencial Brasileiro: Decisões do Conselho Administrativo de Defesa Econômica. Revista de Defesa da Concorrência, v. 5, n. 2, p. 51-74, nov. 2017.

JORNAL OFICIAL DA UNIÃO EUROPEIA. Processo AT.39685 - Fentanilo. Resumo da Decisão da Comissão de 10 de dezembro de 2013 relativa a um processo nos termos do artigo $101^{\circ}$ do Tratado sobre o Funcionamento da União Europeia. Bruxelas: JO, 29 abr. 2015. Disponível em: <https://eur-lex.europa.eu/legalcontent/PT/TXT/PDF/?uri=CELEX:52015XC0429(03)\&from=EN>. Acesso em: 04 jun. 2018.

KAPCZYNSKI, Amy; PARK, Chan; SAMPAT, Bhaven. Polymorphs and Prodrugs and salts (Oh My!): An Empirical Analysis of "Secondary" Pharmaceutical Patents. PLoS One, v. 7, n. 12, p. 1-9, 2012. Disponível em: $<$ https://www.ncbi.nlm.nih.gov/pmc/articles/PMC3515607/>. Acesso em: 25 nov. 2019.

KEYTE, James A. What It Is and How It Is Being Applied: The "Quick Look" Rule of Reason. Antitrust, v. 11, n. 3, Summer 1997.

KROES, Neelie. Anti-Cartel Enforcement: Criminal and Administrative Policy Panel session. Press Release, Speech. Brasilia, 8th Oct. 2009. Disponível em: $<$ http://europa.eu/rapid/press-release_SPEECH-09-454_en.htm?locale=en $>$. Acesso em: 03 jun. 2018. 
LIMA, Luís Felipe Balieiro (Coord.). Propriedade Intelectual no Direito Empresarial. São Paulo: Quartier Latin, 2009.

LOFTUS, Peter. Pfizer, Takeda to Get \$2.15 Billion Settlement. The Wall Street Journal, New York, 12 June 2013. Disponível em:

$<$ https://www.wsj.com/articles/SB10001424127887324188604578541080995659790>. Acesso em: 9 jul. 2019.

MARQUES, Cláudia Lima. Contratos no Código de Defesa do Consumidor: o novo regime das relações contratuais. 5. ed. rev., atual. e ampl. São Paulo: Revista do Tribunais, 2006.

MARRARA, Thiago. Sistema Brasileiro de Defesa da Concorrência - organização, processos e acordos administrativos. São Paulo: Atlas, 2015.

MEIER, Markus H. Antitrust Concerns and the FDA Approval Process (statement). Before the United States House of Representatives, Judiciary Committee, Subcommittee on Regulatory Reform, Commercial and Antitrust Law, Washington D.C., 27 Jul. 2017. Disponível em:

$<$ https://www.ftc.gov/system/files/documents/public_statements/1234663/p859900_commi ssion_testimony_re_at_concerns_and_the_fda_approval_process_house_7-27-17.pdf $>$. Acesso em: 24 nov. 2019.

MELLO, Patrícia Campos. Defensoria questiona no Cade aumento de 1422\% em remédio para hepatite C. Folha de S.Paulo, 21 out. 2019. Disponível em:

$<$ https://www1.folha.uol.com.br/cotidiano/2019/10/defensoria-questiona-no-cadeaumento-de-1422-em-remedio-para-hepatite-c.shtml>. Acesso em: 25 nov. 2019.

MOURA, Carlos Augusto. Análise de patentes de medicamentos tem novo fluxo. Anvisa. Brasília, 1 jun. 2012. Disponível em: <http://portal.anvisa.gov.br/resultado-debusca?p_p_id $=101 \& p \_p \_l i f e c y c l e=0 \& p \_p \_s t a t e=$ maximized $\& p \_p \_$mode $=v i e w \& p \_p \_c o l$ $\mathrm{id}=$ column-

$1 \& p \_p \_c o l \_c o u n t=1 \& \_101 \_$struts_action $=\% 2 F a s s e t \_p u b l i s h e r \% 2 F v i e w \_c o n t e n t \& \_101 \_a$ ssetEntryId $=2666139 \& \_101$ type $=$ content\&_101_groupId $=219201 \& \_101$ urlTitle $=$ analis e-de-patentes-de-medicamentos-tem-novo-fluxo\&inheritRedirect=true $>$. Acesso em: 12 jun. 2019.

NAGY, Csongor István. The Distinction between Anti-competitive Object and Effect after Allianz: The End of Coherence in Competition Analysis? World Competition, v. 36, n. 4, p. 541-564, 2013.

NISHIJIMA, Marislei; BIASOTO JR., Geraldo; LAGROTERIA, Eleni. A competição no mercado farmacêutico brasileiro após uma década de medicamentos genéricos: uma análise de rivalidade em um mercado regulado. Economia e Sociedade, Campinas, v. 23, n. 1 (50), p. 155-186, jan./abr. 2014.

OCDE. Generic pharmaceuticals and competition. Paris: OECD, 10 Feb. 2015. Disponível em: $<$ http://www.oecd.org/daf/competition/generic-pharmaceuticalscompetition.htm>. Acesso em: 25 nov. 2019.

ODUDU, Okeoghene. Restrictions of Competition by Object: what's the beef?

Competition Law Journal, v. 9, n. 1, p. 11-17, 2009. 
OECD. Directorate for Financial and Enterprise Affairs. Competition Committee.

Executive Summary of the Discussion on Competition and Generic Pharmaceuticals. Cancels \& replaces the same document of 09 January 2015. Paris: OECD, 10 Feb. 2015.

Disponível em:

$<$ http://www.oecd.org/officialdocuments/publicdisplaydocumentpdf/?cote=DAF/COMP/M (2014)2/ANN6/FINAL\&doclanguage=en>. Acesso em: 2 abr. 2019.

OLIVEIRA, Glauco Avelino Sampaio de. Indicadores de Concorrência. Brasília: CADE, set. 2014, p. 8-16. Disponível em: <http://www.cade.gov.br/acesso-a-

informacao/publicacoes-institucionais/dee-publicacoes-anexos/documento-de-trabalho-n01-2014-indicadores-de-concorrencia.pdf>. Acesso em: 19 jul. 2019.

PEEPERKORN, Luc. Defining "by object" restrictions. Concurrences, n. 3, p. 40-50, 2015.

PEREIRA, Paulo Sérgio Velten. Função social da empresa e do contrato. Revista eletrônica de ciências jurídicas da Associação do Ministério Público do Estado do Maranhão, São Luiz, maio 2005.

PITOFSKY, Robert. Why Dr. Miles Was Right. AEI Journal on Government and Society, p. 27-30, Jan./Feb. 1984.

POSNER, Richard A.; William M. Landes. The Economic Structure of Intellectual Property Law. Cambridge: The Belknap Press of Harvard University Press, 2003.

PRAŠNIKA, Janez; ŠKERLJ, Tina. New product development process and time-to-market in the generic pharmaceutical industry. Proceedings of the Fifth Asia Pacific Industrial Engineering and Management Systems Conference 2004, v. 35, n. 6, p. 690-702, 2006.

PRÓGENÉRICOS. Associação Brasileira das Indústrias de Medicamentos Genéricos. Mercado. São Paulo, 2019. Disponível em: <http://progenericos.org.br/mercado >. Acesso em: 25 nov. 2019.

. Associação Brasileira das Indústrias de Medicamentos Genéricos. Genéricos em números. São Paulo, 2019. Disponível em: $<$ http://progenericos.org.br/dados-do-setor $>$. Acesso em: 25 nov. 2019.

RBC CAPITAL MARKETS. Pharmaceuticals: Analyzing Litigation Success Rates. Toronto: RBC, 15 Jan. 2010. Disponível em: $<$ https://amlawdaily.typepad.com/pharmareport.pdf $>$. Acesso em: 9 ago. 2019.

REICHMANN, Jerome H. Legal Hybrids Between the Patent and Copyright Paradigms. Columbia Law Review, v. 94, n. 8, p. 2432-2558, 1994.

RODRIGUES, Silvio. Direito Civil - Parte Geral. v. 1, 28. ed. São Paulo: Saraiva, 1998.

ROSENBERG, Barbara; BERARDO, José Carlos da Matta; BECKER. Bruno Bastos. Análise prévia de atos de concentração quatro anos depois. O que nós advogados aprendemos? In: CARVALHO, Vinicius Marques de (Org.). A Lei 12.529/2011 e a Nova Política de Defesa da Concorrência. São Paulo: Singular, 2015. p. 159-180, p. 170. 
ROSENVALD, Nelson; FARIAS, Cristiano Chaves de. Curso de Direito Civil - Parte Geral e LINDB. v. 1, 12. ed. São Paulo: JusPodivm, 2014.

ROSINA, Mônica Steffen Guise. A regulamentação internacional das patentes e sua contribuição para o processo de desenvolvimento do Brasil: análise da produção de novos medicamentos no setor farmacêutico. 2011. Tese (Doutorado em Direito) Universidade de São Paulo, São Paulo, 2011.

SALOMÃO FILHO, Calixto. Direito Concorrencial. São Paulo: Malheiros, 2013.

. Direito concorrencial: as condutas. São Paulo: Malheiros, 2007.

. Direito industrial, direito concorrencial e interesse público. Revista de Direito

Público da Economia (RDPE), Belo Horizonte: Fórum, v. 2, n. 7, p. 29-44, jul./set. 2004.

. Função social do contrato: primeiras anotações. Revista de Direito Mercantil, Industrial, Econômico e Financeiro, São Paulo, v. 42, n. 132, p. 7-24, out/dez. 2003. 2015.

Teoria crítico-estruturalista do direito comercial. São Paulo: Marcial Pons,

SANTANA, Selma Pereira de. A Culpa Temerária. Contributo para uma construção no direito penal brasileiro. São Paulo: Revista dos Tribunais, 2005.

SANTOS, Manoel J. Pereira dos. Software: Acesso Ao Código Fonte e Transferência de Tecnologia. In: DEL NERO, Patrícia Aurélio. (Org.) Propriedade Intelectual e Transferência de Tecnologia. Belo Horizonte: Fórum, 2010.

SCHILDKRAUT, Marc G. Patent-Splitting Settlements and the Reverse Payment Fallacy. Antitrust Law Journal, v. 71, n. 3, p. 1033-1068, 2004.

SHAPIRO, Carl. Antitrust limits to patent settlements. RAND Journal of Economics, v. 34, n. 2, p. 391-411, Summer 2003.

SHAVEL, Steven; TANGUY, Van Ypersele. Rewards Versus Intellectual Property Rights. Journal of Law and Economics, v. 44, p. 525-547, out. 2001. Disponível em: $<$ http:/www.law.harvard.edu/faculty/shavell/pdf/44_J_Law_Econ_525.pdf $>$. Acesso em: 25 nov. 2019.

SHERMAN, Bernard C. Testimony. In: COMMITTEE ON ENERGY AND

COMMERCE. House of Representatives. Committee on Energy and Commerce.

Subcommittee on Commerce, Trade, and Consumer Protection. Congress, 111., $1^{\text {st }}$

Session. The Protecting Consumer Access to Generic Drugs of 2009. Washington, DC: 31 Mar. 2009, Serial n. 111-125. p. 216-229. Disponível em:

$<$ https://archive.org/details/gov.gpo.fdsys.CHRG-111hhrg67822/page/n234>. Acesso em: 2 ago. 2019.

SILVEIRA, Newton; BORGES BARBOSA, Denis. Uma Introdução à Propriedade Intelectual. 2. ed., rev. e atual. Rio de Janeiro: Lumen Juris, 2003.

SOKOL, Daniel. The transformation of vertical restraints: per se illegality, the rule of reason, and per se legality. Antitrust Law Journal, n. 3, p. 1003-1016, 2014. 
THOMAS, John R. Pharmaceutical Patent Law. 2. ed. Arlington, VA: BNA Books, 2010.

TRIBUNAL GERAL DA UNIÃO EUROPEIA. Comunicado de Imprensa n⿳0 90/16. Luxemburgo, 8 set. 2016. Disponível em:

$<$ https://curia.europa.eu/jcms/upload/docs/application/pdf/2016-09/cp160090pt.pdf $>$. Acesso em: 04 jun. 2018.

UNITED STATES SUPREME COURT. Eastern Railroad Presidents Conference v. Noerr Motors. Argued: Decided: February 20, 1961, n. 50.

VIEGAS, Juliana Laura Bruna. Contratos típicos de propriedade industrial: contratos de cessão e de licenciamento de marcas e patentes; licenças compulsórias. In: SANTOS Manoel J. Pereira dos Santos; JABUR, Wilson Pinheiro (Coords.). Contratos de Propriedade Industrial e Novas Tecnologias. São Paulo: Saraiva, 2007. p. 55-142 (Série GVlaw).

VILLARDI, Pedro. Panorama do status patentário e registro sanitário dos medicamentos antirretrovirais no Brasil - Implicações para o acesso e para a política industrial de saúde. Rio de Janeiro: ABIA, 2012.

WEBBER, Marianne Mendes. Direito da concorrência e cooperação jurídica internacional. Belo Horizonte: Arraes, 2015.

WELZEL, Hans. El nuevo sistema del Derecho Penal - Una introducción a la doctrina de la acción finalista. Traducción de José Cerezo Mir. Barcelona: Ariel, 1964.

WHISH, Richard. Competition Law. $6^{\text {th }}$ ed. Oxford: Oxford University Press, 2008.

YORK, Julia K. Reverse-Payment Litigation in the Wake of FTC v. Actavis. ABA Section of Antitrust Law, Intellectual Property Committee Newsletter, v. 4, n. 5, Winter 2014. 
ANEXOS 
Anexo 1: Economia dos consumidores entre 2001 e 2019 devido aos genéricos

Figura 8: Economia dos consumidores entre 2001 e 2019 devido aos genéricos Economia

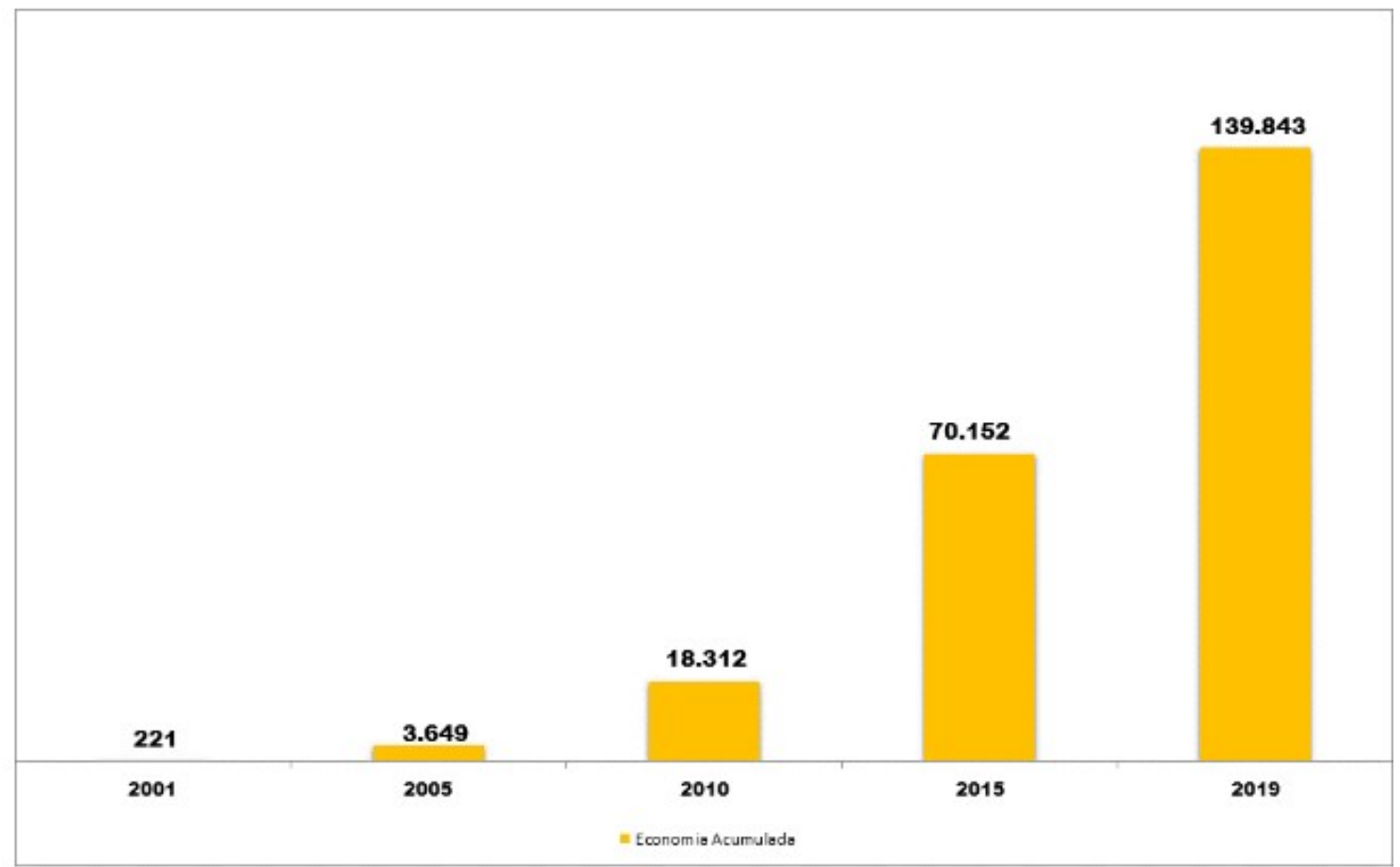

Fonte: PróGenéricos 
Anexo 2: Evolução dos acordos de patente pré e pós decisão Actavis

Figura 9: Evolução dos acordos de patente pré e pós decisão Actavis

\begin{tabular}{|c|c|c|c|c|c|c|c|c|c|c|c|c|}
\cline { 2 - 12 } & FY2004 & FY2005 & FY2006 & FY2007 & FY2008 & FY2009 & FY2010 & FY2011 & FY2012 & FY2013 & FY2014 & FY2015 \\
\hline Final Settlements & 14 & 11 & 28 & 33 & 66 & 68 & 113 & 156 & 140 & 145 & 160 & 170 \\
\hline Potential Pay for Delay & 0 & 3 & 14 & 14 & 16 & 19 & 31 & 28 & 40 & 29 & 21 & 14 \\
\hline $\begin{array}{c}\text { Potential Pay for Delay (excluding } \\
\text { Solely Litigation Fees } \\
\text { million) }\end{array}$ & 0 & 3 & 13 & 14 & 15 & 11 & 17 & 25 & 33 & 15 & 11 & 5 \\
\hline $\begin{array}{c}\text { Potential Pay for Delay } \\
\text { Involving First Filers }\end{array}$ & 0 & 2 & 9 & 11 & 13 & 15 & 26 & 18 & 23 & 13 & 11 & 7 \\
\hline
\end{tabular}

Fonte: FTC. ${ }^{538}$

${ }^{538}$ FEDERAL TRADE COMMISSION. Agreements Filed with the Federal Trade Commission under the Medicare Prescription Drug, Improvement, and Modernization Act of 2003: Overview of Agreements Filed in FY 2015 - A Report by the Bureau of Competition. Washington, DC: FTC, Nov. 2017. 
Anexo 3: Concorrência de genéricos e preço de medicamentos

Figura 10: Concorrência de genéricos e preço de medicamentos

Generic Competition and Drug Prices

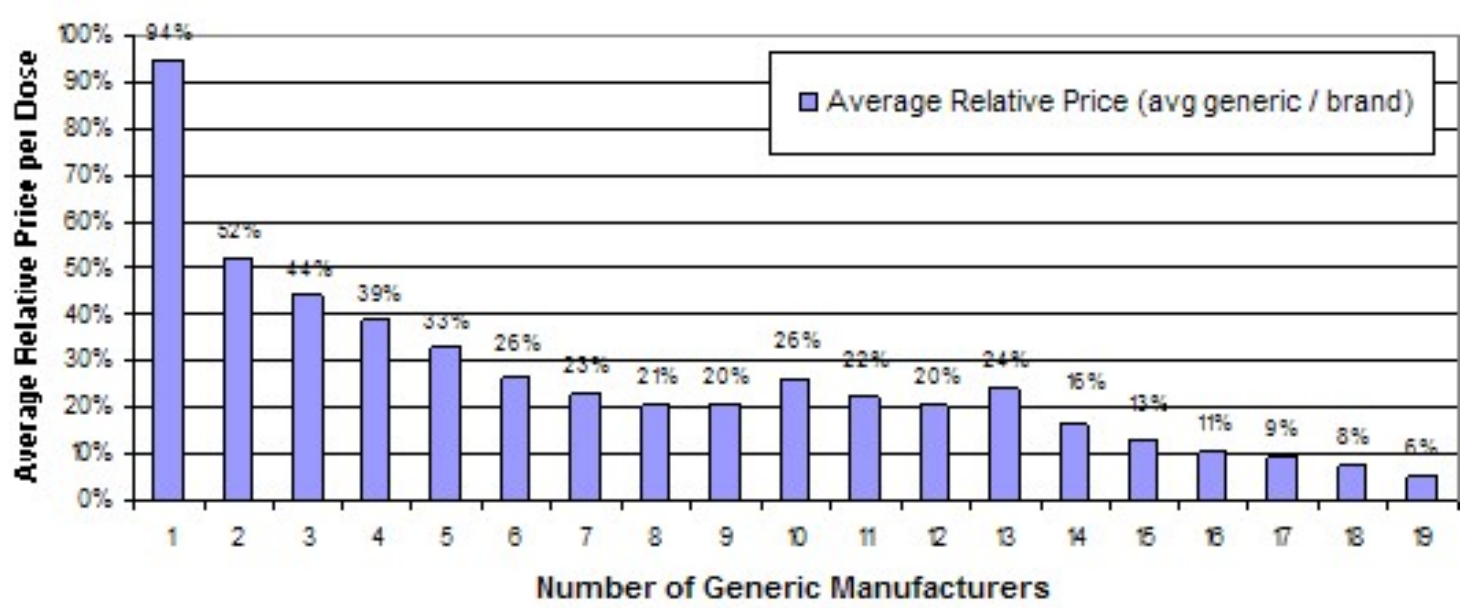

Fonte: FOOD AND DRUG ADMINISTRATION. FDA analysis of retail sales data from IMS Health. IMS National Sales Perspective (TM), 1999-2004. Washington, DC, Feb. 2005. 


\section{Anexo 4: Lista de Medicamentos: Primeiro registro na ANVISA em resposta à solicitação da autora}

\section{LISTA DE MEDICAMENTOS}

\section{Primeiro registro na ANVISA em resposta à solicitação da autora}

1- Cardizem (CD);

Detalhes do

registro

Empresa: INST DE ANGELI PRODS TERAPEUTICOS LTDA

Publicação: Resolução n²9/ANVISA de 19/11/1986 - pg:17272

Ver publicação original no DOU

Produto: CARDIZEM

Apresentação: 60 MG COM CT FR VD AMB X 25

Registro: 017601520046

Processo: 131683 (agrupar: por processo)

Classificação: 030203

Complemento: COMPRIMIDOS SIMPLES

Petição: 30

2- Citrato de Tamoxifeno;

Detalhes do

registro

Empresa: FARMITALIA CARLO ERBA S/A

Publicação: Resolução n6/ANVISA de 02/06/1988 - pg:9939

Ver publicação original no DOU

Produto: CITRATO DE TAMOXIFENO

Processo: 25001.002164/87 (agrupar: por processo)

Registro: 1.0386.0085.002-1 (agrupar: por família / por apresentação)

Apresentação: 10 MG COM CX FR X 250 USO HOSPITALAR

Classificação: 0702005

Petição: 106 
3- Lamictal;

\section{Detalhes do}

registro

Empresa: LABORATÓRIO WELLCOME ICI LTDA.

Publicação: Portaria ANVISA de 12/12/1991 - pg:28731-28734

Ver publicação original no DOU

Produto: LAMICTAL

Processo: 25992.005685/72 (agrupar: por processo)

Registro: 1.1618.0050.008-1 (agrupar: por família / por apresentação)

Apresentação: 200 MG COM CT 6 BL AL PLAST X 10

Classificação: 0903019 ANTICONVULSIVANTES

Petição: 180

Validade: $36 \mathrm{M}$

Vencimento: 0696

4- Esomeprazol - dados relativos aos medicamentos das empresas Ranbaxy e Astrazeneca;

Detalhes do

registro

Empresa: RANBAXY FARMACÊUTICA LTDA

Publicação: Resolução n³19/ANVISA de 30/01/2012 - pg:S-41

Ver publicação original no DOU

Produto: ESOMEPRAZOL MAGNÉSIO

Classificação: ANTIULCEROSOS

Referência: NEXIUM

Processo: 25351.007552/2010-09 (agrupar: por processo)

Vencimento: $02 / 2017$

Destinação: COMERCIAL

Registro: 1.2352.0219.019-7 (agrupar: por família / por apresentação)

Validade: 24 Meses

Apresentação: 40 MG COM REV CT BL AL/PLAS OPC X 28

Petição: 155 GENERICO - REGISTRO DE MEDICAMENTO 
Detalhes do

registro

Empresa: ASTRAZENECA DO BRASIL LTDA.

Publicação: Resolução n512/ANVISA de 29/12/2000 - pg:93

Ver publicação original no DOU

Produto: ESOMEPRAZOL MAGNÉSIO TRIIDRATADO

Complemento: NEXIUM

Processo: 25351.011156/00-11 (agrupar: por processo)

Registro: 1.1618.0105.002-6 (agrupar: por família / por apresentação)

Apresentação: 20 MG COM CT BL AL/AL X 7

Vencimento: 12/2005

Classificação: 0102040 ANTIULCEROSOS

Validade: 36 MESES

Petição: 175 REGISTRO DE NOVO PRODUTO

5- Lipitor;

Detalhes do

registro

Empresa: WARNER-LAMBERT IND. COM. LTDA.

Publicação: Portaria n²66/ANVISA de 08/04/1998 - pg:15-17

Ver publicação original no DOU

Produto: ATORVASTATINA CALCICA

Complemento: LIPITOR

Processo: 25000.006460/97-14 (agrupar: por processo)

Registro: 1.0024.0117.018-9 (agrupar: por família / por apresentação)

Apresentação: 40 MG COM REV CT FR PLAS OPC X 30

Classificação: 0109045 ANTILIPEMICOS

Petição: 150

Validade: $24 \mathrm{M}$

Vencimento: 0403 
6- Efexor (XR);

Detalhes do

registro

Empresa: LABORATÓRIOS WYETH-WHITEHALL LTDA

Publicação: Portaria nº0/ANVISA de 22/05/1995 - pg:7241-7242

Ver publicação original no DOU

Produto: VENLAFAXINA

Complemento: EFEXOR

Processo: 25000.012893/93-11 (agrupar: por processo)

Registro: 1.2110.0074.001-6 (agrupar: por família / por apresentação)

Apresentação: 25 MG COM CT BL AL PLAST INC X 30

Classificação: 0904015 ANTIDEPRESSIVOS

Petição: 175

Validade: $36 \mathrm{M}$

Vencimento: 0500

7- Stavigile;

Detalhes do

registro

Empresa: LIBBS FARMACÊUTICA LTDA

Publicação: Resolução n5349/ANVISA de 30/11/2009 - pg:780-796

Ver publicação original no DOU

Produto: STAVIGILE

Expediente: 068940098

Petição: 1331 MEDICAMENTO NOVO - Atualização de Especificações e/ou Metodologia Analítica

Nota: Petição de alteração pós-registro de medicamento anuida pela RESOLUÇÃO-RE No 5.349 , DE 27 DE NOVEMBRO DE 2009, publicada no DOU de 30/11/2009 
8- Androgel

Detalhes do

registro

Empresa: LABORATORIO ENILA IND COM DE PRODS QUIM FARMAC SA

Publicação: Resolução n³95/ANVISA de 08/03/2002 - pg:97

Ver publicação original no DOU

Produto: TESTOSTERONA (PORT. 344/98 LISTA C 5)

Complemento: ANDROGEL

Processo: 25351.001834/01-47 (agrupar: por processo)

Registro: 1.2205.0041.001-4 (agrupar: por família / por apresentação)

Destinação: Comercial

Apresentação: 1 PCC GEL TOP CX CT BG AL CT 50 G + DOS GRAD

Vencimento: 03/2007

Classificação: 0502006 HORMONIOS SEXUAIS EXCLUSIVE OCITOCICOS

Validade: 24 MESES

Petição: 174 REGISTRO DE FORMA FARMACÊUTICA NOVA NO PAÍS

9- Cipro - dados relativos aos medicamentos da empresa Bayer;

Detalhes do

registro

Empresa: BAYER DO BRASIL LTDA

Publicação: Resolução n5/ANVISA de 09/05/1988 - pg:8024

Ver publicação original no DOU

Produto: CIPRO

Processo: 25001.005028/87 (agrupar: por processo)

Registro: 1.0429.0056.008-9 (agrupar: por família / por apresentação)

Apresentação: 750 MG COM REV CT FR X 20

Classificação: 0708003

Petição: 106 
10- Stilnox - dados relativos aos medicamentos da empresa Sanofi;

\section{Detalhes do}

registro

\section{Empresa: LABORATÓRIOS FARMACÊUTICOS ESPASIL LTDA.}

Publicação: Portaria n²2/ANVISA de 02/03/1994 - pg:2976-2983

Ver publicação original no DOU

Produto: HEMITARTARATO DE ZOLDIPEM

Complemento: STILNOX

Processo: 25000.018049/92 (agrupar: por processo)

Registro: 1.0149.0079.001-0 (agrupar: por família / por apresentação)

Apresentação: 10 MG COM REV CT E BL X 10

Classificação: 0905046 HIPNOTICOS

Petição: 175

Validade: $04 \mathrm{~A}$

11- Omeprazol;

Detalhes do

registro

Empresa: LIBBS FARMACÊUTICA LTDA

Publicação: Portaria n55/ANVISA de 06/12/1990 - pg:23485-23487

Ver publicação original no DOU

Produto: PEPRAZOL

Nome OMEPRAZOL

Comercial:

Processo: 25000.000150/90 (agrupar: por processo)

Registro: 1.0033.0055.002-6 (agrupar: por família / por apresentação)

Apresentação: 20 MG COM

Classificação: 0102040 ANTIULCEROSOS

Validade: $24 \mathrm{M}$

Vencimento: 09/95

Petição: 128 
12- Fentanil;

\begin{tabular}{|c|c|}
\hline $\begin{array}{l}\text { Detalhes do } \\
\text { registro }\end{array}$ & \\
\hline Empresa: & CENTRAL DE MEDICAMENTOS - MPAS \\
\hline Publicação: & Resolução ANVISA de 28/05/1982 - pg:9759 \\
\hline & Ver publicação original no DOU \\
\hline Produto: & FENTANIL \\
\hline Classe: & 09.01.01.03.00.0 \\
\hline $\begin{array}{l}\text { Código da } \\
\text { Forma: }\end{array}$ & 20102.2 \\
\hline Apresentação: & $50 \mathrm{FA} 10 \mathrm{ml}$ \\
\hline Processo: & 437681 (agrupar: por processo) \\
\hline $\begin{array}{l}\text { Código de } \\
\text { Operação: }\end{array}$ & 21 \\
\hline Registro: & $11.00038 / 82$ \\
\hline $\begin{array}{r}\text { Número da } \\
\text { Apresentação: }\end{array}$ & 1 \\
\hline Relação: & $38 / 82$ \\
\hline
\end{tabular}

13- Citalopram;

Detalhes do

registro

Empresa: MERCK S/A

Publicação: Resolução n³432/ANVISA de 05/11/2007 - pg:S-23

Ver publicação original no DOU

Produto: CITALOPRAM

Classificação: ANTIDEPRESSIVOS

Complemento: CITALOPRAM

Processo: 25351.162782/2002-91 (agrupar: por processo)

Vencimento: 08/2007

Destinação: COMERCIAL

Registro: 1.0089.0286.001-2 (agrupar: por família / por apresentação)

Validade: 24 Meses

Apresentação: 20 MG COM REV CT BL AL PLAS INC X 20

Petição: 140 CADUCIDADE DE REGISTRO DE MEDICAMENTO 
14- Perindopril.

Detalhes do

registro

Empresa: INCIBRA PRODUTOS FARMACÊUTICOS LTDA

Publicação: Portaria n9/ANVISA de 13/01/1997 - pg:693-697

Ver publicação original no DOU

Produto: PERINDOPRIL

Complemento: COVERSYL

Processo: 25000.015667/89 (agrupar: por processo)

Registro: 1.1278.0051.002-3 (agrupar: por família / por apresentação)

Apresentação: 4 MG COM CT BL AL PLAS INC X 30

Vencimento: $01 / 2002$

Classificação: 306002 ANTI-HIPERTENSIVOS

Validade: 24 MESES

Petição: 175 REGISTRO DE NOVO PRODUTO

15- Hytrin.

Detallhes do

registro

Empresa: ABBOTT LABORATÓRIOS DO BRASIL LTDA

Publicação: Portaria n²07/ANVISA de 10/05/1996 - pg:8079-8084

Ver publicação original no DOU

Produto: TERAZOSIN

Complemento: HYTRIN

Processo: 25001.003471/86 (agrupar: por processo)

Registro: 1.0553.0184.003-5 (agrupar: por família / por apresentação)

Apresentação: 2 MG COM CT BL AL PLAS INC X 20

Classificação: 0306010

Petição: 184

Validade: $36 \mathrm{M}$

Vencimento: 1099 